Aus der Klinik für Kardiologie und Pneumologie

(Prof. Dr. med. G. Hasenfuß)

der Medizinischen Fakultät der Universität Göttingen

\title{
Interobserver-Agreement zwischen Pneumologen und dem Zytopathologen, die identische TBNA-Ausstriche bewertet haben
}

\author{
INAUGURAL-DISSERTATION \\ zur Erlangung des Doktorgrades \\ der Medizinischen Fakultät der \\ Georg-August-Universität zu Göttingen
}

vorgelegt von

Tobias Anslinger

aus

Homburg (Saar)

Göttingen 2018 
Dekan:

Prof. Dr. rer. nat. H.K. Kroemer

Referent/in

Prof. Dr. med. S. Andreas

Ko-Referent/in:

Prof. Dr. med. H.-U. Schildhaus

Datum der mündlichen Prüfung: $\quad$ 08.08.2019 
Hiermit erkläre ich, die Dissertation: „Interobserver-Agreement zwischen Pneumologen und dem Zytopathologen, die identische TBNA-Ausstriche bewertet haben" eigenständig angefertigt und keine anderen als die von mir angegebenen Quellen und Hilfsmittel verwendet zu haben.

Göttingen, den

(Unterschrift) 


\section{Inhaltsverzeichnis:}

Inhaltsverzeichnis:..................................................................

Abbildungsverzeichnis:..........................................................II

Tabellenverzeichnis:.............................................................II

Abkürzungsverzeichnis:..................................................................................II

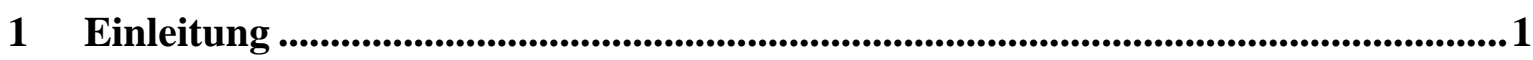

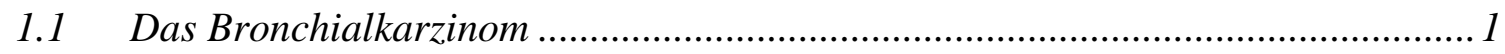

1.1.1 Definition und Klassifikation des Bronchialkarzinoms ................................ 1

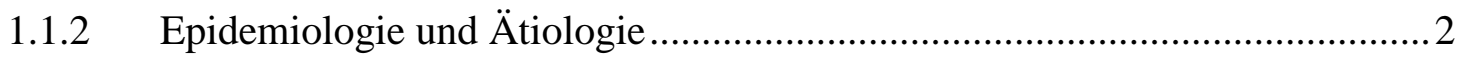

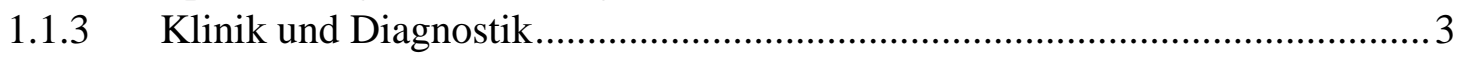

1.1.4 Therapieansätze und Prognose bei SCLC und NSCLC ................................. 4

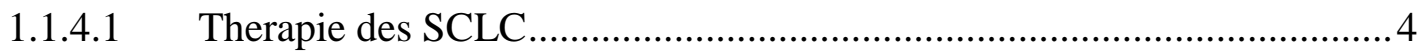

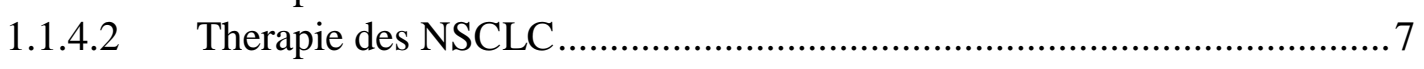

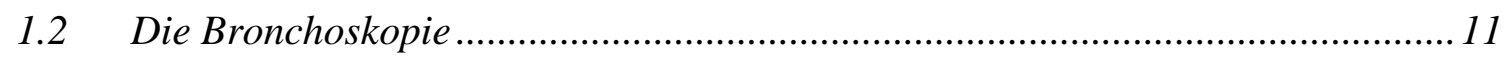

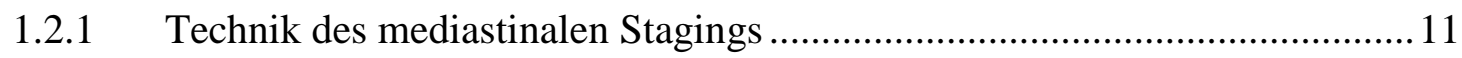

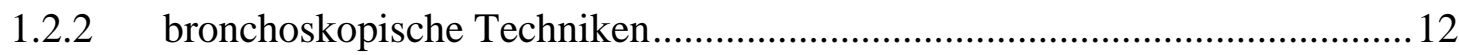

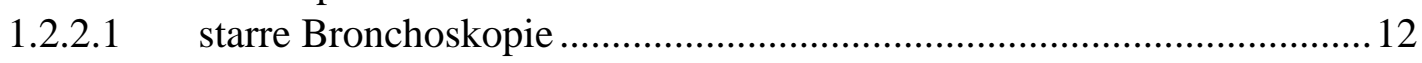

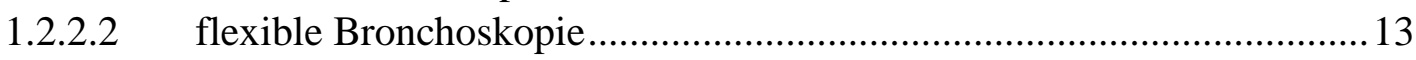

1.2.3 Diagnostik zentraler Läsionen ............................................................... 14

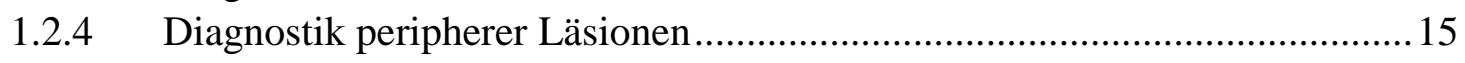

1.2.5 Bedeutung der TBNA in Diagnose und Therapie.......................................... 16

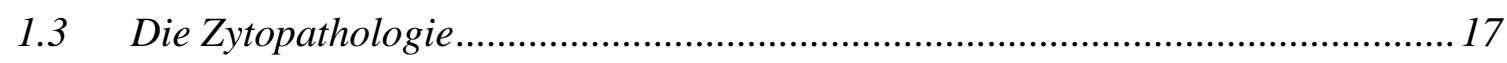

1.4 Die Rolle des Pneumologen in der Behandlung von Lungenkrebs ....................... 20

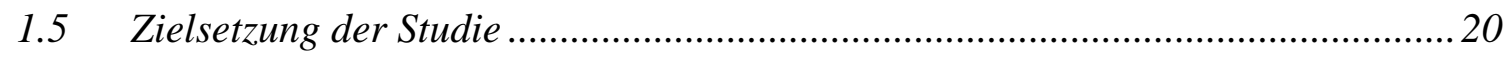

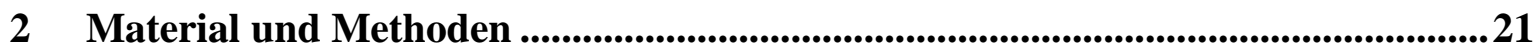

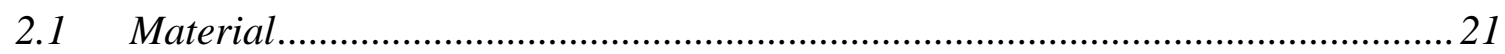

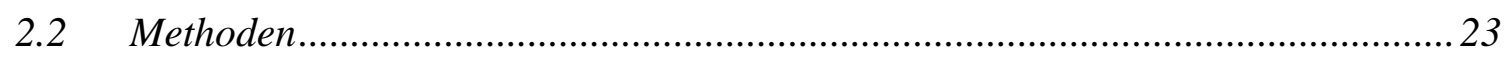

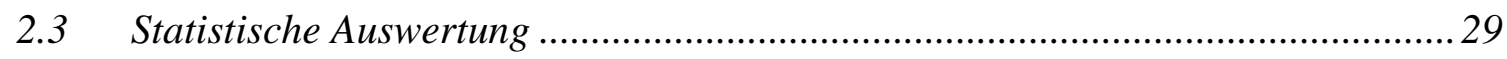

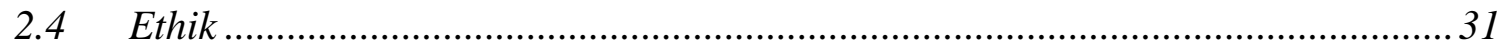

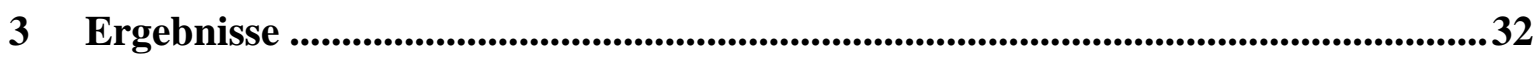

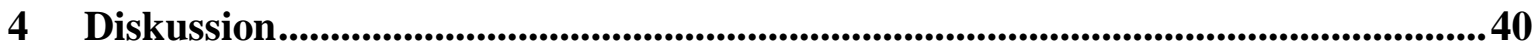

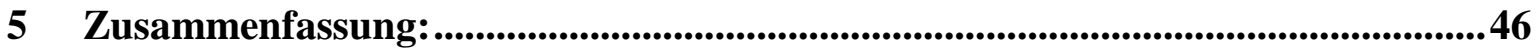

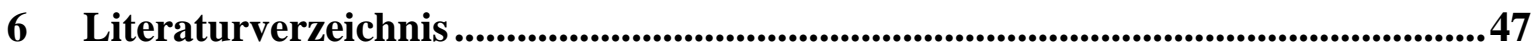




\section{Abbildungsverzeichnis:}

Abbildung 1: SCLC aus EBUS-TBNA, May-Grünwald-Färbung (Präparat der

Lungenfachklinik Immenhausen, freundlicherweise überlassen von Dr. Rittmeyer) 17

Abbildung 2: Adenocarcinom aus EBUS-TBNA, May-Grünwald-Färbung (Präparat der Lungenfachklinik Immenhausen, freundlicherweise überlassen von Dr. Rittmeyer) ......... 18 Abbildung 3: verhornendes Plattenepithelkarzinom aus EBUS-TBNA, May-GrünwaldFärbung (Präparat der Lungenfachklinik Immenhausen, freundlicherweise überlassen von Dr. Rittmeyer).

Abbildung 4: Flowchart zur Übersicht der Datenaufarbeitung .......................................23

Abbildung 5: Entscheidungsstufen der zytologischen Untersuchung ................................25

Abbildung 6: Definition der Gruppe mit chirurgischer Validierung ................................. 27

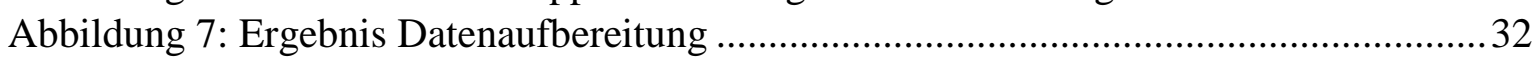

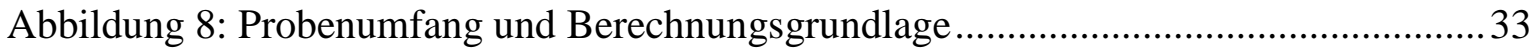

\section{Tabellenverzeichnis:}

Tabelle 1: Tabellenvorlage für die Übereinstimmungsberechnung .................................2 29

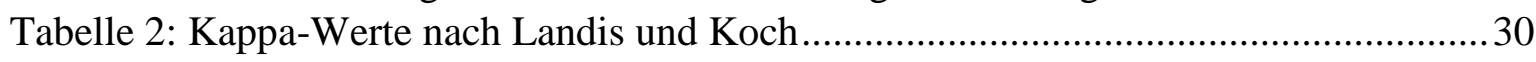

Tabelle 3: Vierfeldertafel zur Beurteilung eines binären Klassifikators ............................. 31

Tabelle 4: Vergleich der beiden Datensätze mit Fokus auf Malignität der Proben.

Interobserver-Agreement: beachtlich/substantial $(\kappa=0,72$, CI 0.69-0.75) ........................... 34

Tabelle 5: Vergleich der beiden Datensätze mit Fokus auf Malignität der Proben.

Interobserver-Agreement: beachtlich/substantial $(\kappa=0.80$, CI 0.74-0.86) .......................... 35

Tabelle 6: Vergleich der beiden Datensätze mit Fokus auf: SCLC vs. NSCLC.

Interobserver-Agreement: vollkommen/almost perfect $(\kappa=0.89$, CI $0.76-1.03) \ldots \ldots \ldots \ldots \ldots . . . . . .36$

Tabelle 7: Vergleich der beiden Datensätze mit Fokus auf PEC vs ADC vs NOS.

Interobserver-Agreement: ausreichend/fair $(\kappa=0.32$, CI 0.21-0.43) .................................. 37

Tabelle 8: Vergleich der beiden Datensätze mit Fokus auf PEC vs. Nicht-PEC.

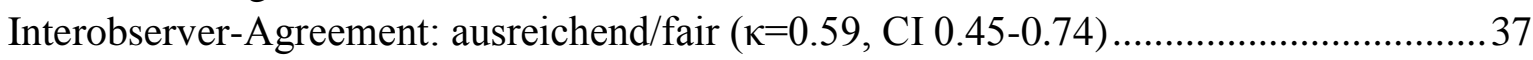

Tabelle 9: untersucherspezifische Sensitivität und Spezifität gemessen an der chirurgisch validierten Subgruppe

Tabelle 10: Kappa-Werte unserer Daten im Vergleich mit den drei anderen Studien, die Interobserver-Agreement für TBNA untersucht haben. 


\section{Abkürzungsverzeichnis:}

SCLC

NSCLC

PEC

NOS

TBNA

EBUS

LK

IML

$\kappa$

LKI

L.W.

NA small cellular lung cancer

non-small cellular lung cancer

Plattenepithelkarcinom

not otherwise specified

transbronchiale Nadelaspiration

endobronchialer Ultraschall

Lymphknoten

isolierte mediastinale Lymphadenopathie

Kappa

Lungenklinik Immenhausen

Lutz Welker (Zytopathologe)

not available 


\section{Einleitung}

Das Bronchialkarzinom ist die am häufigsten ursächlich zum Tode führende Krebserkrankung. Aufgrund fehlender Frühsymptome ist die rasche Diagnostik für die Therapieentscheidung von hoher Bedeutung. Die endgültige Beurteilung der befallenen Lymphknotenstationen ist im klinischen Alltag die Domäne der Bronchoskopie. Bei peripher unauffälligem PET-CT (M0-Status) und vermeintlich lokal begrenzter Erkrankung scheiden sich am N2-Status in der Regel die primär operablen Fälle von den primär inoperablen. $\mathrm{Ob}$ diese zytologische Unterscheidung von Zytopathologen und geschulten Pneumologen gleichermaßen bewältigt werden kann, ist Inhalt dieser Studie.

\subsection{Das Bronchialkarzinom}

\subsubsection{Definition und Klassifikation des Bronchialkarzinoms}

Der Begriff Bronchialkarzinom (Synonym: Lungenkarzinom) beschreibt eine heterogene Gruppe von neoplastischen Erkrankungen der Lunge. Unterschieden wird, den klinischen Therapieoptionen geschuldet, primär in kleinzellige $(\mathrm{SCLC}=$ small cellular lung cancer; ca $15 \%)$ und nicht nichtkleinzellige Bronchialkarzinome (NSCLC $=$ non-small cellular lung cancer; ca 85\%). Die NSCLC lassen sich noch weiter differenzieren in Plattenepithelkarzinome, Adenokarzinome, und großzellige Karzinome. Großzellige Karzinome sind wiederum ein Sammelbegriff für mehrere, insgesamt aber selten auftretende Entitäten.

Histologisch lassen sich sieben Entitäten aus Lungenursprungsgewebe unterscheiden, welche sich in ca. 30 verschiedene Varianten aufteilen lassen (Goeckenjan et al. 2010). Es kommt vor, dass mehr als ein Bronchialkarzinom de novo in der gleichen Lungen entsteht, sogar, dass in einem Bronchialkarzinom mehrere Entitäten zu finden sind. Dies ist ein Grund, warum die Diagnostik komplex ist. 


\subsubsection{Epidemiologie und Ätiologie}

Weltweit sterben jährlich etwa eine Million Menschen am Bronchialkarzinom. In Entwicklungsländern steigt die Bronchialkarzinommortalität, während sie in Nordamerika und Europa für Männer sinkt, bei Frauen allerdings steigt. Das Bronchialkarzinom ist die am häufigsten zum Tode führende Krebserkrankung. In Deutschland steht bei Männern das Bronchialkarzinom an erster Stelle der Krebstodesursachen. Bei Frauen wird Schätzungen zufolge 2015 Brustkrebs wahrscheinlich als häufigste Krebstodesursache vom Bronchialkarzinom abgelöst werden (Malvezzi et al. 2015). Dies ist durch die sich ändernden Rauchgewohnheiten zu erklären. Bei kaum einer anderen Erkrankung sind die Risikofaktoren und die Inzidenz der Krankheit so deutlich korreliert wie bei Lungenkrebs. Jedes Jahr sterben in Deutschland rund 42000 Menschen an Lungenkrebs, im Jahr 2013 beispielsweise waren es 44813 (Statistisches Bundesamt (Destatis) 2014). Die Inzidenz betrug im Jahr 2010 in Deutschland 87,9/100000 für Männer und 40,9/100000 für Frauen (Robert-Koch-Institut 2013). Die Diagnose wird meist zwischen dem 55. und 60. Lebensjahr gestellt. Die 5-Jahres-Überlebenswahrscheinlichkeit liegt trotz moderner Medizin nur zwischen 14 und 19\% (Robert-Koch-Institut 2013).

Der Tabakkonsum ist der größte Risikofaktor. Rund 90\% der Bronchialkarzinome können dem Rauchen zugeschrieben werden. 9 bis $15 \%$ der Lungenkrebsfälle werden arbeitsplatzassoziierten Noxen zugeschrieben, wie beispielsweise Asbest, Chrom, Arsen, Nickel, polyzyklische aromatische Kohlenwasserstoffe und Kohleverbrennungsprodukte, Noxen, deren karzinogenes Risiko sich bei gleichzeitigem Tabakkonsum potenziert. Dabei gehen über 90\% der berufsbedingten Bronchialkarzinome auf Asbestexposition zurück. Andere in der Umwelt vorkommende Noxen, wie Radon, Diesel- und Industrieabgase machen mit ca 5\% einen vergleichsweise geringen Anteil aus. (Goeckenjan et al. 2010)

Im Tabakrauch sind über 4000 chemische Verbindungen zu finden, von denen mindestens 50 als Karzinogene nachgewiesen sind (Smith et al. 2000b; Smith et al. 2000a). Der Tabakrauch schädigt kaum unmittelbar physikalisch. Allerdings schlägt sich das Aerosol auf der bronchialen Schleimhaut nieder, diffundiert in die Zellen und reagiert dort chemisch mit der DNA. Dadurch werden, insbesondere bei fehlerhaften, gehemmten oder beschädigten DNA-Reparaturmechanismen verschiedene, oft irreversible Mutationen ausgelöst. Gleichzeitig werden durch Stimulation verschiedener Proteinsignalkaskaden Hyperplasien, Metaplasien und Dysplasien begünstigt (Akopyan and Bonavida 2006). 
Insbesondere die Modulation an Signalwegen, die wichtige Onkogene und Tumorsupressorgene beeinflussen sind kritisch. Darunter fallen das Onkogen K-ras (Hoffmann et al. 1993; Belinsky et al. 1989) und das Tumorsupressorgen p53 (Denissenko et al. 1996). Entscheidend für das Erkrankungsrisiko sind dabei die angesammelten Packungsjahre: Pack-Years. Ein Pack-Year entspricht dem Konsum von 20 Zigaretten pro Tag für ein Jahr (Goeckenjan et al. 2010).. Auch Passivrauchen ist nachweislich schädlich (Boffetta et al. 1998).

\subsubsection{Klinik und Diagnostik}

Die hohe Letalität der Erkrankung erklärt sich dadurch, dass sie erst spät, meist zu spät, erkannt wird. Spezifische Frühsymptome gibt es nicht. Husten, Dyspnoe, Thoraxschmerz und Gewichtsverlust treten zwar häufig initial häufig auf, sind aber unspezifisch. Plötzlich aufgetretene Knochenschmerzen und diverse paraneoplastische Syndrome gelten als Spätsymptome und sind meist Zeichen der Inoperabilität. Etwa 15\% der Erkrankten haben zum Zeitpunkt der Diagnosestellung Beschwerden.

Zur Basisdiagnostik bei Verdacht auf Bronchialkarzinom gehören eine ausführliche Anamnese unter besonderer Berücksichtigung der Raucheranamnese und Arbeitsplatzanamnese, klinische Untersuchung mit Augenmerk auf der kardiopulmonalen und körperlichen Leistungsfähigkeit, Laboruntersuchungen, EKG und Röntgen Thorax in zwei Ebenen. Wichtig ist auch die Lungenfunktionsuntersuchung, um die Möglichkeit einer Operation zu eruieren. Zur Lokalisationsdiagnostik des Primarius wird meist ein Spiral-CT oder eine PET-CT Untersuchung durchgeführt.

Zum Nachweis der Erkrankung reichen die Spezifitäten der bildgebenden Verfahren nicht aus. Eine histologische Diagnosesicherung ist zwar der Goldstandard, allerdings genügt unter praktischen Aspekten des klinischen Alltags und der oft inoperablen Ausgangssituation oftmals ein zytologischer Nachweis der Erkrankung mittels Bronchoskopie. Dieses Vorgehen wird im Kapitel Bronchoskopie ausführlich beschrieben. Alternativ und ergänzend können Pleurapunktionen/biopsien oder ultraschall- oder CTgesteuerte transthorakale Punktionen durchgeführt werden. Thorakoskopien oder offene Biopsien im Rahmen einer Thorakotomie sind invasivere Verfahren mit denen im Zweifelsfall histologisches Material gewonnen werden kann. 
Präoperativ muss ein Staging durchgeführt werden. Neben der Frage nach der funktionellen Durchführbarkeit einer Lobektomie in Bezug auf das verbleibende Lungenvolumen, stellt sich die Frage nach dem Erkrankungsstadium. Dabei sind die mediastinalen Lymphknoten von entscheidender Bedeutung. Zwar können mit der hervorragenden Sensitivität des PET-CT selbst nicht vergrößerte Lymphknoten als verdächtig eingestuft werden, allerdings gelingt ein definitiver Nachweis des Lymphknotenbefalls auf diese Art nicht. Ergänzend muss eine möglichst CT-geplante, idealerweise ultraschallgesteuerte Bronchoskopie (EBUS) mit gezielter Feinnadelaspirationszytologie (EBUS-TBNA) der verdächtigen mediastinalen Lymphknoten durchgeführt werden. Der Ausschluss von Fernmetastasen hingegen gelingt am effektivsten mittels PET-CT. Das Vorgehen von bronchoskopischer Diagnostik und Staging wird im Kapitel 1.2. „Die Bronchoskopie“ weiter ausgeführt.

\subsubsection{Therapieansätze und Prognose bei SCLC und NSCLC}

Für das Bronchialkarzinom gibt es grundlegend die gleichen Behandlungsmöglichkeiten, wie bei allen anderen Neoplasien. Da es sich aber um eine sehr heterogene Gruppe handelt, unterscheiden sich die entitätsspezifischen Behandlungsstrategien grundlegend.

\subsubsection{Therapie des SCLC}

SCLC machen 15\% aller Bronchialkarzinome aus. Sie wachsen sehr schnell (Verdopplungszeit: ca. 10 bis 50d) und sind bei Diagnosestellung normalerweise schon disseminiert, sodass eine Resektion meist nicht möglich ist. Eingeteilt wird wegen praktischer Aspekte neben TNM und UICC in drei Kategorien: „Very limited disease“(nach UICC: T1-2, N0-1; ca 5\% d.F.), „limited disease“(nach UICC: T3-4N0-1 und T1-4N2-3; ca 20\% d.F.) und „extensive disease“(nach UICC:M1, ca 75\% d.F.). Die mittlere Überlebenszeit liegt unbehandelt nur bei 3 Monaten. Durch angemessene Behandlung lässt sich diese bei Metastasierung auf 8 bis 12 Monate verlängern und bei limited disease auf 14 bis 20 Monate strecken. Obwohl ein Langzeitüberleben über 5 Jahre extrem selten ist $(<1 \%)$, liegt die rezidivfreie 5-Jahres-Überlebensrate bei disseminierter Erkrankung zwischen 10 und 20\% (Goeckenjan et al. 2010; Lassen et al. 1995; Souhami and Law 1990; Colice et al. 2003). Prognostisch relevant sind Allgemeinzustand des 
Patienten (Albain et al. 1990) und das Vorhandensein von Komorbiditäten, insbesondere deren Ausprägung (Ludbrook, Joanna J S et al. 2003). Bis zum 75. Lebensjahr ist Alter an sich prognostisch nicht relevant. Frauen haben eine etwas günstigere Prognose als Männer (Wolf et al. 1991; Singh et al. 2005).

Aufgrund der hohen Teilungsrate und der frühen Metastasierungsneigung wird meist primär ein systemisches Vorgehen mittels Polychemotherapie und Strahlentherapie durchgeführt.

Chemotherapie bei SCLC

Das unverzügliche Einsetzen der Chemotherapie ist wichtig. Ein Abwarten bis zum symptomatischen Progress sollte vermieden werden (Earl et al. 1991). Einen nachgewiesenen Nutzen haben Cisplatin, Carboplatin, Etoposid, Teniposid, Cyclophosphamid, Ifosfamid, Vincristin, Methotrexat, Adriamycin, Epirubicin, Paclitaxel, Irinoteca, Topotecan und Bendamustin. Kombinationschemotherapieprotokolle haben höhere Ansprechraten als Monotherapien (Lowenbraun et al. 1979; Alvarado-Luna and Morales-Espinosa 2016), wobei eine duale Primärtherapie aufgrund des günstigeren Nebenwirkungsprofils bevorzugt wird (Chan and Coward, Jermaine I G 2013). Platinhaltige Protokolle sind nicht-platinhaltigen Protokollen überlegen (Karim and Zekri 2012; Sundstrom et al. 2002). Etoposid ist der wahrscheinlich wirksamste Kombinationspartner (Mascaux et al. 2000; Pujol et al. 2000) mit in Studien belegter Wirksamkeitsverstärkung (Jett et al. 1990; Jackson, D V Jr et al. 1984). Auf Anthrazykline wird eher verzichtet werden, da diese Schemata bei simultaner Radiatio mit einer signifikant höheren Toxizität belastet sind (Gregor et al. 1997; Perry et al. 1987). Nach dem ersten Zyklus kann bereits das Ansprechen beurteilt werden. Bei Krankheitsprogress sollte unverzüglich auf eine andere Therapie umgestellt werden (Goeckenjan et al. 2010; Wolf et al. 1987). Ein primär alternierender Therapieplan hat gegenüber einem Therapiewechsel bei Progress keinen Vorteil (Postmus et al. 1996; Urban et al. 1999). Insgesamt werden 4 bis 6 Zyklen Chemotherapie durchgeführt, je nach Ausmaß der Erkrankung. Dabei bewirkt ein längeres Therapieschema die Verlängerung des progressionsfreien Überlebens, nicht jedoch das Gesamtüberleben (Goeckenjan et al. 2010; Spiro et al. 1989; Sculier et al. 1998). Im palliativen Stadium sind die Symptomkontrolle und die Lebensqualität von der Kombinationsbehandlung (White et al. 2000), Standarddosierung, iv-Applikation (Souhami et al. 1997) und insbesondere dem Ansprechen (Gatzemeier et al. 1994) der Chemotherapie abhängig. 
Strahlentherapie bei SCLC

Die zusätzliche Radiatio bei SCLC verlängert die 3-Jahres-Überlebensrate um 5\% (Pignon et al. 1992; Warde and Payne 1992). Es gibt keinen Vorteil eines simultanen gegenüber eines alternierenden Vorgehens bei der Radiochemotherapie. Das Langzeitüberleben war in allen Studien niedrig $(<15 \%)$, die Toxizität bei Simultantherapie erhöht (Perry et al. 1998; Lebeau et al. 1999). Im Vergleich zum konsekutiven Ablauf von Radiochemotherapie zeigt sich allerdings ein Vorteil im 3-Jahres-Überleben für ein Simultanes Vorgehen bei erhöhter Toxizität (McCracken et al. 1990; Thomas, C R Jr et al. 2001). Weiter ist der frühe Beginn der Radiatio von Bedeutung (Pijls-Johannesma, M C G et al. 2005; Ruysscher et al. 2006). Nach Möglichkeit sollte eine simultane Radiochemotherapie durchgeführt werden (Goeckenjan et al. 2010). Eine Rauchabstinenz während der simultanen Radiochemotherapie verbessert die Prognose (Videtic, Gregory M $M$ et al. 2003). Eine Schädelbestrahlung trägt prophylaktisch und bei primär bestehenden Hirnmetastasen zum progressfreien und symptomfreien Intervall bei (Seute et al. 2006; Postmus et al. 2000) und sollte bei allen Patienten durchgeführt werden (Goeckenjan et al. 2010). Auch die Überlebenszeit verlängert sich dadurch nachweislich (Slotman et al. 2007; Slotman et al. 2009).

Operative Therapie bei SCLC

Eine alleinige Operation ist unzureichend (Fox and Scadding 1973). Operative Maßnahmen müssen mit Chemotherapie kombiniert werden (Osterlind et al. 1985; Waddell and Shepherd 2004). In mehreren Studien mit primärer Operation und adjuvanter Chemotherapie ergaben sich bei histologisch gesichertem N0-Status 3Jahresüberlebenszeiten die denen von NSCLC-Patienten entsprechen. Bereits bei der Gruppe mit N1-Status verschlechtern sich im Vergleich mit NSCLC allerdings die Überlebenszeiten und bei mediastinalem Befall lag die 3-Jahres Überlebensrate bei nur $20 \%$ (Ulsperger et al. 1991; Tsuchiya et al. 2005). Eine prophylaktische Schädelbestrahlung bei Patienten mit Remission nach Abschluss der Chemotherapie reduziert nachweislich das Auftreten von Hirnmetastasen (Arriagada et al. 2002). Auch die 5-Jahres-Überlebensrate erhöht sich signifikant (Meert et al. 2001).

In den wenigen Fällen, in denen eine N0 oder N1 Situation zum Diagnosezeitpunkt besteht, sollte eine Operation durchgeführt werden. Da dieses Vorgehen nicht mit prospektiven Studien belegt ist, sollte im Hinblick auf die postoperative Funktion und Lebensqualität auf eine Pneumektomie verzichtet werden. Weiter muss vor dem Eingriff 
mittels PET-CT ein weiterer Lymphknotenbefall ausgeschlossen werden (Goeckenjan et al. 2010). Ob die obligat folgende Chemotherapie neoadjuvant oder adjuvant erfolgt, ist unwichtig (Shepherd et al. 1991).

In der Mehrzahl der Erkrankungsfälle haben invasive Verfahren palliative, Symptomkontrollierende und -lindernde Aufgaben. Zwar kann durch die Polychemotherapie häufig eine vollständige Remission erreicht werden, Rezidive sind allerdings häufig. Die Chemotherapie ist obligat, bei kompletter Remission ist eine prophylaktische Hirnbestrahlung indiziert.

\subsubsection{Therapie des NSCLC}

Ein NSCLC liegt bei $85 \%$ der Bronchialkarzinome vor. Die beiden häufigsten Untergruppen sind das Adenokarzinom (eher peripher lokalisiert, ca. 40\% d.F.) und das Plattenepithelkarzinom (eher zentral lokalisiert, ca. 25\% d.F.). Großzellige Karzinome (ca $10 \%$ d.F.), adenosquamöse Karzinome, sarkomatoide Karzinome und Karzinoide sind selten (Travis 2002; Hoffman et al. 2000).

Das primäre Therapieziel bei NSCLC ist die kurativ intendierte Operation. Die richtige Indikationsstellung ist von großer Bedeutung. Nicht nur der Tumor muss in einem operablen Stadium sein, sondern auch die respiratorische Reserve nach der Operation (Lungenparenchymverlust) und die resultierende Rechtsherzbelastung (Gesamtquerschnittsverkleinerung der Lungenstrombahn) sind limitierende Faktoren. Als guter Prädiktor im Hinblick auf postoperative Komplikationen haben sich im Vergleich zu einzelnen Komorbiditäten sogenannte Komobiditätsscores erwiesen (Birim et al. 2003). Dagegen hat höheres Alter allein keinen negativen Einfluss auf das postoperative Outcome (Sawada et al. 2005). Die Komorbiditätsscores haben im Gegensatz zum Alter am ehesten einen prädiktive Aussagekraft (Colinet et al. 2005).

Operatives Therapie bei NSCLC

Die Operation ist in den frühen Stadien UICC I und II indiziert, die R0 Resektion mit ausreichendem Resektionsrand ist das Ziel. Die 5-Jahres-Überlebensraten liegen im Stadium IA zwischen 69 bis 89\% (Mountain 1997), im Stadium IB zwischen 52 bis $75 \%$ (Okada et al. 2004). Bei befallenem N1-Status (Befall von intrapulmonalen und/oder hilären Lymphknoten) sinken die 5-Jahres-Überlebensraten auf 45 - 52\% (Stadium IIA), 
33\% (StadiumIIB) und 24 - 44\% (StadiumIIA) (Mountain 1997; Okada et al. 2004). Die perioperative Letalität liegt bei etwa 3,5\% (1\% bis 7,6\%) (Detterbeck 2001). Die perioperative Letalität nimmt mit dem Alter zu (Weinmann et al. 2003). Größere Eingriffe sind mit höherem perioperativem Risiko verbunden (Detterbeck 2001; Wahi et al. 1989), allerdings auch mit geringeren Rezidivraten (Ginsberg and Rubinstein 1995). Limitierte Resektionen scheinen bei Tumoren kleiner $2 \mathrm{~cm}$ in Bezug auf die Langzeitprognose gleichwertig (Okada et al. 2001; Villamizar and Swanson 2014) und sollte Patienten, die aufgrund ihrer Komorbiditäten keine Lobektomie verkraften würden, angeboten werden. Ähnlich verhält es sich mit der Manschettenresektion, bei der bei zentral sitzenden Tumoren im Gegensatz zur Pneumektomie ein Großteil des Lungengewebes erhalten werden kann. Trotz leicht erhöhter Lokalrezidivrate (Detterbeck 2001) kann sie wegen Vermeidung der Spätfolgen von Pneumektomien und bei signifikant verlängertem medianen Überlebenszeiten (Ferguson and Lehman 2003) auch bei funktionell nicht eingeschränkten Patienten angewandt werden (Goeckenjan et al. 2010). Die systematische Lymphknotendissektion im Stadium I führt zu akkuratem Staging und eventuell zu einer Prognoseverbesserung, weswegen sie als Standardtherapieverfahren eingesetzt wird (Wright et al. 2006). Bei brustwandinfiltrierenden Tumoren (T3) ist die Radikalität der chirurgischen Maßnahme (Magdeleinat et al. 2001; McCaughan et al. 1985) ein signifikanter Prognosefaktor. Dabei ist vor Allem die chirurgische Technik ausschlaggebend (Downey et al. 1999). Bei fehlender Rippeninfiltration ist auch eine extrapleurale Lyse möglich. Für die Stadien IIIA und IIIB kann bei Patienten mit gutem Allgemeinzustand unter bestimmten Voraussetzungen (Subklassifizierung nach Robinson) eine kurative Operation angestrebt werden. Auch im palliativen Stadium kann die Indikation zu Resektionen, Lob- und Pneumektomie, Pleurodesen sowie orthopädischen und neurochirurgische Eingriffen gestellt werden (Goeckenjan et al. 2010).

\section{Chemotherapie bei NSCLC}

Eine adjuvante Chemotherapie verbessert in den Stadien II und IIIA nachgewiesenermaßen das 5-Jahres-Überleben um 4,1 bis $15 \%$, sowie das progressfreie Überleben um 5,1 bis 12\% (Arriagada et al. 2004; Winton et al. 2005; Douillard et al. 2006). Es konnte bestätigt werden, dass cis-Platin-haltige Therapiepläne eine Steigerung der Überlebensrate um 4 bis $5,4 \%$ nach sich ziehen (Sedrakyan et al. 2004; Pignon et al. 2008). Bei adjuvanter Chemotherapie im Stadium II lassen sich deutliche Überlebensvorteile beobachten (5JÜR von bis zu 52\%) (Douillard et al. 2006). Eine adjuvante Chemotherapie sollte 60 Tage nach R0-Resektion mit systematischer Lymphknotendissektion allen Patienten mit Stadium II 
und IIIA gegeben werden (Goeckenjan et al. 2010). Im Stadium IB muss bei bislang unzureichender Datenlage eine individuelle Terapieentscheidung gefällt werden. Eine aktuelle Metaanalyse zeigt allerdings eine Verbesserung im Overall-Survival und im progressionsfreien Überleben (Chen et al. 2015). Die Therapie sollte 4 Zyklen und eine cis-Platin-haltige Chemotherapie-Kombination umfassen (Goeckenjan et al. 2010). Je weiter fortgeschritten das Stadium ist, umso bedeutender wird die Chemotherapie für das Therapiekonzept. Die Grenze der Operabilität befindet sich im Bereich der klinisch orientierten Subklassifizierung nach Robinson (Robinson et al. 2007). Werden Komorbiditäten nicht berücksichtigt, verläuft die Grenze bei den Stadien IIIA und IIIB, welche ebenfalls eine Kombinationschemotherapie mit mehreren Zyklen nach sich ziehen (Goeckenjan et al. 2010). Cis-Platin, Etoposid und Vionorelbin haben bisher die beste Datenlage (Arriagada et al. 2004). In den palliativen Stadien (IV und meist IIIB) verbessern sich durch Chemotherapie nachweislich sowohl die Lebensqualität als auch das Langzeitüberleben im Vergleich zur Best supportive Care (Ranson et al. 2000; Spiro et al. 2004). Auch in der palliativen Situation scheint cis-Platin, sowohl Überlebenszeit als auch -qualität betreffend, am wirksamsten (Thongprasert et al. 1999; Ranson et al. 2000). Weiter zeigt sich, dass Pemetrexed als Kombinationspartner von Platin im Vergleich zu Gemcitabine in fortgeschrittenen Stadien das Langzeitüberleben verbessert (Pilkington et al. 2015).

\section{Targeted Therapie bei NSCLC}

Neben der konventionellen Chemotherapie gibt es auch biochemische Angriffspunkte, wie Tyroskinase-Signalwege und Oberflächenproteine. Grundlage hierfür sind pharmakogenomische Fortschritte, die durch neue molekularbiologische Verfahren, wie das Next-Generation-Sequencin möglich wurden. Mit nur einer Probe kann auf mehrere selektierte Alterationen gleichzeitig geprüft werden. Durch den geringen Materialaufwand wird diese Methode in klinischem Alltag und Forschung Eingang finden und u.E. nach Prädiktoren für Ansprechen oder Versagen von Therapiemaßnahmen definieren (Moreira and Eng 2014). Die prädiktiven Parameter, welche Patienten von der Behandlung profitieren müssen zum großen Teil noch erforscht werden. Bei Einsatz des VEGFAntikörpers Bevacizumab verbessert sich in den fortgeschrittenen Stadien bei Kombination mit Chemotherapie die Remissionsraten und das progressfreie Überleben (Sandler et al. 2006; Reck et al. 2010). Bei Erreichen einer Remission verbessert Permetrexet in Kombination mit Bevacizumab das progressionsfreie Überleben im Vergleich zum Antikörper allein (Barlesi et al. 2013). Für den EGFR-Antikörper 
Cetuximab wurde in der Kombination mit einer 2-fach Chemotherapie ein Vorteil im medianen Überleben gezeigt (Pirker et al. 2009), hohe EGF-Rezeptorexpression konnte als positiver Prädiktor im Hinblick auf das Gesamtüberleben unter first line Cetuximab in Kombination mit Chemotherapie ausgemacht werden (Pirker et al. 2012). Der EGFRezeptor-Tyrosinkinaseinhibitor Gefitinib zeigte als Solotherapie im Vergleich mit einer platinhaltigen 2-fach-Chemotherapie einen deutlichen Vorteil im progressionsfreien Überleben (Mok et al. 2009).

Radiotherapie bei NSCLC

Eine adjuvante Bestrahlung wird nach R0 Resektion im Stadium I und II nicht durchgeführt. Bei Inoperabilität ist die definitive Radiotherapie hingegen Mittel der Wahl (Goeckenjan et al. 2010), wobei eine hyperfraktionierte akzelerierte Bestrahlung die Überlebenszeit verbessert (Rowell and Williams 2001). Im Stadium III ist die perioperative Bestrahlung Gegenstand aktueller Forschung. Therapiealgorythmen werden erstellt. Bei deutlich erhöhter Letalität konnte bei Patienten mit primär resektablen Tumoren mit neoadjuvanter Radio/-Chemotherapie im Vergleich zur definitiven Radiochemotherapie ein signifikant längeres progressionsfreies Überleben nachgewiesen werden (Albain et al. 2009). Außerhalb von Studien können resektable Stadium-III-Patienten auch individuell mit Induktionsradiatio behandelt und anschließend operiert werden (Goeckenjan et al. 2010). Bei N2-Befall, sowie im Falle von R1/2 Resektion wird eine zusätzliche Bestrahlung des Mediastinums empfohlen (Goeckenjan et al. 2010).Im Stadium III hat sich die klinisch orientierte Subklassifizierung zur Beschreibung des N2 Status nach Robinson durchgesetzt (Robinson et al. 2007). Hier verläuft die Grenze der Operabilität, also zwischen kurativer und palliativer Intention. Für zukünftige Therapiealgorythmen werden, vor allem in diesen Stadien, multimodale Behandlungskonzepte vergleichend erforscht. Die Ganzhirnbestrahlung bei Auftreten von Hirnmetastasen im palliativen Stadium erzielt häufig eine partielle Remission (Suh et al. 2006; Mehta et al. 2003) und meist eine Symptomverbesserung (Tsao et al. 2006). Bei zusätzlicher stereotaktischer Einzeitbestrahlung von einzelnen Metastasen verbessert sich die Prognose und der Karnovsky-Status, während sich Cortison- und Chemotherapiebedarf verringern (Andrews et al. 2004; Tsao et al. 2012). Nach Operation bewirkt ab Stadium III die prophylaktische Bestrahlung des Schädels eine Reduktion an auftretenden Hirnmetastasen (Pottgen et al. 2007; Gore et al. 2011) und wird daher empfohlen. 
Insbesondere in den palliativen Situationen sind die Maßnahmen in einem effektiv organisierten Betreuungskontext durchzuführen, der interdisziplinär angelegt sein sollte, sodass Entscheidungen schnell und kompetent - unter Einbeziehung des Patienten und dessen Angehörigen - getroffen und umgesetzt werden können (Goeckenjan et al. 2010).

In jüngster Vergangenheit wurden deutliche Fortschritte bei der Wahl der Agentien erzielt, die immer definiertere Anwendungsbereiche bekommen. Da die Chemotherapie primär nach dem histologischen Subtyp ausgewählt wird, ist die adäquate Probengewinnung noch wichtiger. Weiter ist bei eGFR-positiven Befunden die „targeted therapie“ eine grundlegende Säule des Behandlungskonzeptes (Detterbeck et al. 2013).

\subsection{Die Bronchoskopie}

\subsubsection{Technik des mediastinalen Stagings}

Das Prinzip der Tumorabklärung in der Pneumologie besteht darin, den Lungenkrebs zu diagnostizieren und im gleichen Schritt das Tumorstadium festlegen zu können, während man die sichersten, am wenigsten invasiven und günstigsten Verfahren anwendet (Yung, Rex C W 2003).

Die Mediastinoskopie ist eine endoskopische Operation unter Vollnarkose, die bis vor kurzem das Verfahren der Wahl zum präoperativen Lymphknotenstaging darstellte. Dabei wird durch einen Schnitt in der Fossa Jugularis ein starres Rohr eingebracht, durch welches die mediastinalen Lymphknotenstationen begutachtet, biopsiert oder exstirpiert werden können.

Seit 1983 wird die TBNA als neues, weniger invasives Verfahren angewandt (Wang and Terry 1983), stetig weiter standardisiert und operationalisiert (Wang 1994; van der Heijden, Erik H F M et al. 2014). Wegen geringerer Komplikationsraten, dem Fehlen von absoluten Kontraindikationen und der Möglichkeit auf eine Vollnarkose zu verzichten, hat die TBNA/EBUS-TBNA bei mittlerweile gleichwertigen oder besseren Testwahrscheinlichkeiten die Mediastinoskopie quasi verdrängt. (Um et al. 2015) 


\subsection{2 bronchoskopische Techniken}

Die Bronchoskopie spielt bei der Diagnostik maligner, wie auch benigner Prozesse der Lunge eine zentrale Rolle. Von einem primären Therapeutikum hat sie sich zu einem intensiv genutzten Diagnostikum in der Pneumologie entwickelt. So wurde das Verfahren in den ersten Jahren nach seinem Debüt im Jahre 1887 (Killian 1898) primär zur Fremdkörperentfernung genutzt und um postinfektiös narbig verengte Atemwege zu dilatieren (Herth 2011). Ab 1976 wurde sie auch zur Kryoresektion und Rekanalisierung von exophytisch wachsenden Tumoren benutzt (Hetzel et al. 2008). Heute hat sich das Anwendungsspektrum zu Gunsten der Diagnostik verschoben. Gegenwärtig werden verschiedene bronchoskopische Techniken angewandt, ständig weiterentwickelt und getestet. Jede hat ihre spezifischen Vor- und Nachteile und muss gezielt, entsprechend der Fragestellung, ausgewählt werden.

\subsubsection{1 starre Bronchoskopie}

Die erste Bronchoskopie wurde 1897 von Gustav Kilian in Freiburg durchgeführt. Die erste Therapeutische Anwendung bestand im Bergen von aspirierten Fremdkörpern und war damals eine bahnbrechende Entwicklung. Aspirationen waren weitaus schwieriger zu behandeln und hatten oftmals gravierende Folgen. Viele Patienten litten nach Fremdkörperaspiration unter Atelektasen, chronischen Pneumonien und Hämorrhagien, denen viele erlagen (Bolliger und Mathur 2000). In den frühen Jahren der Bronchoskopie waren die Indikationen vorwiegend therapeutischer Art. Es wurden Fremdkörper entfernt und narbige Strikturen, die als Folge von Infektionskrankheiten auftraten, dilatiert. Die benutzten Apparaturen bestanden aus nicht viel mehr als einem starren Rohr, das bei überstrecktem Kopf in die Trachea eingeführt wurde, einer Kopflampe und verschiedenen Greifinstrumenten. Der Patient wurde mit Kokain als Lokalanästhetikum und zusätzlich Morphin oder Chloroform zur Sedierung behandelt. Im frühen 20. Jahrhundert wurden die bronchoskopischen Techniken weiter verfeinert und die starre Bronchoskopie entwickelt (Jackson Ch. 1938).

Die starre Bronchoskopie wird heute unter Vollnarkose durchgeführt. Dabei wird ein etwa $40 \mathrm{~cm}$ langes und 9-13 mm breites Tubusrohr in Trachea und Hauptbronchien eingeführt. Gleichzeitig wird über dieses Rohr beatmet und gearbeitet. Mit den starren Optiken können verschiedene Blickwinkel eingestellt werden und kräftige Zangen zu Entnahme für 
Biopsien und zur Entnahme großer Fremdkörpern benutzt werden (Arastéh und Baenkler 2009). Obwohl die flexible Bronchoskopie die starre Bronchoskopie in den meisten Fällen ersetzt hat, ist die starre Bronchoskopie in bestimmten Situationen überlegen (Wahidi et al. 2007). Bei Atemwegsverengung kann die flexible Bronchoskopie durch Erhöhung des Atemwiderstands unmöglich werden. Die starre Bronchoskopie allerdings kann in solchen Fällen wegen der geringeren Obstruktion angewandt werden. Weiter ist die Saugkraft höher, was die Arbeit an potentiell hämorrhagischen Läsionen erleichtert. Ebenso ist durch das starre Rohr das Zurückdrängen von Tumormassen möglich (Wahidi et al. 2007; Herth, Felix J. F und Ernst 2005; Folch and Mehta 2008). Neue Behandlungsansätze, wie Lasertherapie und Stenteinlagen machen die starre Bronchoskopie wieder attraktiver (Herth und Eberhardt 2004).

\subsubsection{2 flexible Bronchoskopie}

Das flexible Bronchoskop besteht aus einem etwa 4-6mm dicken beweglichen Schlauch. Die optischen Signale werden mittels Fiberglas oder optischem Sensor übertragen. Die Spitze des flexiblen Bronchoskops lässt sich heben und senken, sodass man auch abgewinkelte bronchiale Abgänge gut einsehen kann. Es gibt einen Arbeitskanal, über den Medikamente appliziert werden oder Instrumente wie Zangen oder Nadeln eingeführt werden können. Über diesen Kanal können auch Sekretverhalte, überschüssiges Lokalanästhetikum, Schleim und Spülflüssigkeiten aufgesaugt werden.

Die flexible Bronchoskopie wurde in den späten 60er Jahren von Dr. Shigeto Ikeda (Ohata 1998) entwickelt und hat sich zur hauptsächlich genutzten Technik bei der Abklärung der Verdachtsdiagnose Lungenkrebs entwickelt. Meist wird sie als diagnostisches Mittel eingesetzt. Mit ihrer Hilfe gewinnt man Gewebe zur Klassifizierung des Tumors mittels Histologie oder Zytologie. Sie liefert insbesondere Erkenntnisse für das Staging und für die Entscheidung über Behandlungsoptionen. Die flexible Bronchoskopie ist ein einfach anzuwendendes, sicheres und vom Patienten gut toleriertes Diagnostikum (Herth 2011). Da für die flexible Bronchoskopie im Gegensatz zur starren Bronchoskopie nur Sedierung gebraucht wird und das Risiko überschaubar ist, hat die flexible Bronchoskopie die Starre als primäre Methode fast vollständig ersetzt (Herth 2011). Durch die flexible Bronchoskopie hat der Untersucher die Möglichkeit, die meisten Bronchien vierter bis sechster Generation zu beurteilen. Dabei können visuelle Aspekte der Mukosa direkt 
beurteilt werden, wie Vaskularisierung und Farbe (Herth 2011). Für die flexible Bronchoskopie gibt es nur wenige relative Kontraindikationen. Dazu zählen therapierefraktäre Hypoxämie, kryptogene Blutungen, schwere pulmonale Hypertension, kardiovaskuläre Instabilität und akute Hyperkapnie (Barlési et al. 2006). Die flexible Bronchoskopie ist ein sicheres Verfahren. Die Komplikationsrate liegt bei 0,12\% und Mortalitätsrate bei 0,04\% (Becker et al. 1998). Durch unsachgemäßen Gebrauch von Benzodiazepinen und Hypnotika als Begleitmedikation während des Eingriffs kann es zu Unregelmäßigkeiten in der Atmung kommen. Risikopatienten können durch eine vorherige arterielle Blutgasanalye identifiziert werden (Becker et al. 1998; Mazzone et al. 2002; ElBayoumi and Silvestri 2008) .

Während der Untersuchung sollte zusätzlich Sauerstoff appliziert werden und die Sauerstoffsättigung unter Monitorkontrolle stehen. Bei kardial vorerkrankten Patienten sollte zusätzlich die Herzaktion am Monitor zu sehen sein und Reanimationsausrüstung bereitstehen (Herth 2011).

Ein zentraler Aspekt in der Diagnostik maligner Erkrankungen ist die diagnostische Ausbeute. Dabei geht es um den Prozentsatz an Probenentnahmen, die sich als tatsächlich diagnostisch relevant erweisen. Die zu erwartende diagnostische Ausbeute hängt von der Tumorlokalisation und der Streuung ab (Herth 2011), wie auch von der angewandten Entnahmetechnik (Gasparini et al. 1995). Zentrale endobronchiale Läsionen haben die höchste diagnostische Ausbeute, während kleinere periphere Läsionen eher schwer zu erreichen sind und nach komplizierteren und zeitaufwändigeren Methoden verlangen. Es ist nicht abschließend geklärt, welche Kombination von histologischen und zytologischen Entnahmearten die optimale diagnostische Ausbeute liefert. Wahrscheinlich ist der maßgebliche Faktor die Expertise im jeweiligen Zentrum (Gasparini et al. 1995; Herth 2011).

\subsubsection{Diagnostik zentraler Läsionen}

Bis zu 70\% der Tumore können allein durch flexible Bronchoskopie visuell ausgemacht werden. Die Wandveränderungen bei peribronchialen Tumoren oder bei submukosaler Infiltration sind oft nur geringfügig, so dass die Bronchialwände eingehend nach charakteristischen Zeichen abgesucht werden müssen. 
Durch technische Weiterentwicklungen, wie die Autofluoreszenz-Bronchoskopie oder das sogenannte „narrow-band-imaging“ können maligne Veränderungen schon im Frühstadium (Dysplasie, Carzinoma in Situ, frühes invasives Karzinom) erkannt werden (Zaric et al. 2013). Zentrale Läsionen werden üblicherweise mit einer Kombination aus bronchialen Waschungen, Bürstungen und endobronchialen Biopsien der Diagnostik zugeführt (Herth 2011)

Für exophytisch wachsende Tumore ergibt sich mit über 90\% die höchste diagnostische Ausbeute. Bei Läsionen, die sichtbar sind, aber nicht exophytisch wachsen, fällt die Ausbeute auf 55\%. Liegt die Läsion außerhalb der optischen Reichweite des Bronchoskops, fällt die Ausbeute noch weiter ab (Mazzone et al. 2002; El-Bayoumi and Silvestri 2008; Govert et al. 1999).

Für sichtbare Läsionen werden einfache Biopsiezangen genutzt. Durch Quetschartefarkte sind manchmal selbst bei visuell eindeutig bösartigen Befunden keine histologischen Ergebnisse feststellbar. Deswegen werden 3-5 Proben auf einmal entnommen und zusätzlich wird die Feinnadelpunktion eingesetzt, da bei dieser Technik tiefer in das Tumorgewebe eingedrungen werden kann und weniger Artefakte auftreten. Durch die Eindringtiefe der Nadel ist auch eine größere Chance gegeben, nicht allein die Kapsel zu biopsieren, sondern einen repräsentativeren Ausschnitt des eigentlichen tiefer liegenden Tumors zu sehen (Govert et al. 1999). Zusätzlich kann mit einer Bürste eine Exfoliativzytologie gewonnen werden oder mit der Kryobiopsie gearbeitet werden (Hetzel et al. 2012).

\subsubsection{Diagnostik peripherer Läsionen}

Um aus peripheren Lungenherden diagnostisch verwertbares Gewebe zu erhalten, ist der Aufwand höher. Da die Läsionen nicht mehr in der Sichtweite des Bronchoskops liegen, muss weitgehend blind punktiert werden.

Aus peripheren Läsionen werden Proben normalerweise mit einer Kombination aus bronchialen Waschungen, Bürstungen, transbronchialer Biopsie und TBNA entnommen (Herth 2011). Durch die Kombination der Entnahmetechniken (Gasparini et al. 1995) und eine vorherige CT-Planung (Harrow et al. 2000) lässt sich die diagnostische Ausbeute peripherer Läsionen erhöhen. 
Die transbronchiale Biopsie mittels Biopsiezange ist die älteste Biopsiemethode. Zu den selten auftretenden Komplikationen der transbronchialen Biopsie zählen unter anderem Pneumothorax und Hämorrhagien (Herth 2011).

Mehrere Studien haben gezeigt, dass die TBNA genutzt werden kann, um diagnostisches Material aus peripheren Läsionen zu gewinnen. Die Ausbeute liegt zwischen 30 und 60\% (Gasparini et al. 1995; Liam et al. 2007; Yung, Rex C W 2003; Ellis 1975). Zusätzliche bronchiale Spülungen können die diagnostische Ausbeute erhöhen und können selbst bei nicht auszuwertenden invasiven Probeentnahmen noch wertvolle Informationen liefern (Schreiber and McCrory 2003; Cortese und McDougall 1979). Es ist sinnvoll alle Probenentnahmetechniken anzuwenden, um die Ausbeute zu maximieren (Gasparini et al. 1995).

Vielversprechende neue Methoden, wie die elektromagnetische Navigation und EBUS könnten die Ausbeute der Untersuchung unabhängig von der Darstellbarkeit unter Durchleuchtung machen. Die Expertise des Untersuchers bleibt ein Unsicherheitsfaktor (Herth 2011).

\subsubsection{Bedeutung der TBNA in Diagnose und Therapie}

Im Fall von nicht-kleinzelligem Lungenkrebs steht oft die Frage nach der Operabilität des Tumors im Fokus. Bis zum UICC Stadium IIB (in manchen Fällen bis zu IIIA), d.h. bis T3 N1 M0 gilt ein Bronchialkarzinom als operabel. Während sich Tumorstadium, stark vergrößerte Lymphknoten und Metastasen mit relativ hoher Sicherheit im CT oder PETCT nachweisen lassen, ist die Operabilitätsgrenze bei nicht vergrößerten, aber befallenen Lymphknoten bei N1 und N2 radiologisch nicht sicher zu stellen. Selbst im PET-CT liegt die Spezifität bei 70 bis 86\% (Ung et al. 2007; Darling et al. 2011; Yasufuku et al. 2006) und ist damit deutlich niedriger als die für TBNA/EBUS-TBNA typischen Bereiche von über 99\% (Adams et al. 2009). Alle PET-positiven Befunde müssen morphologisch (histologisch o. zytologisch) abgeklärt werden. Den Lymphknotenbefall mittels Bildgebung sicher auszuschließen ist unmöglich (Darling et al. 2011). In der diagnostischen Bronchoskopie muss daher geklärt werden, ob Lymphknotenmetastasen in den mediastinalen ipsi- (N2) oder kontralateralen (N3) Lymphknoten nachgewiesen werden können. Ein Befall der mediastinalen Lymphknoten hat einen entscheidenden Einfluss auf das Behandlungskonzept (Goeckenjan et al. 2010). 


\subsection{Die Zytopathologie}

Die Zytopathologie befasst sich mit der Beurteilung einzelner, aus dem Zellverband herausgelöster Zellen. Mehr Aussagekraft hat die Histologie, da bei den deutlich größeren Zellmengen der zusammenhängenden Zellverbände mehr Malignitätskriterien beschrieben werden können, wie beispielsweise Invasionsverhalten, Begrenzungen und Verteilungsmuster der suspekten Zellen. Allerdings ist die Materialgewinnung normalerweise mit mehr Aufwand verbunden, da ganze Gewebestücke gewonnen werden müssen.

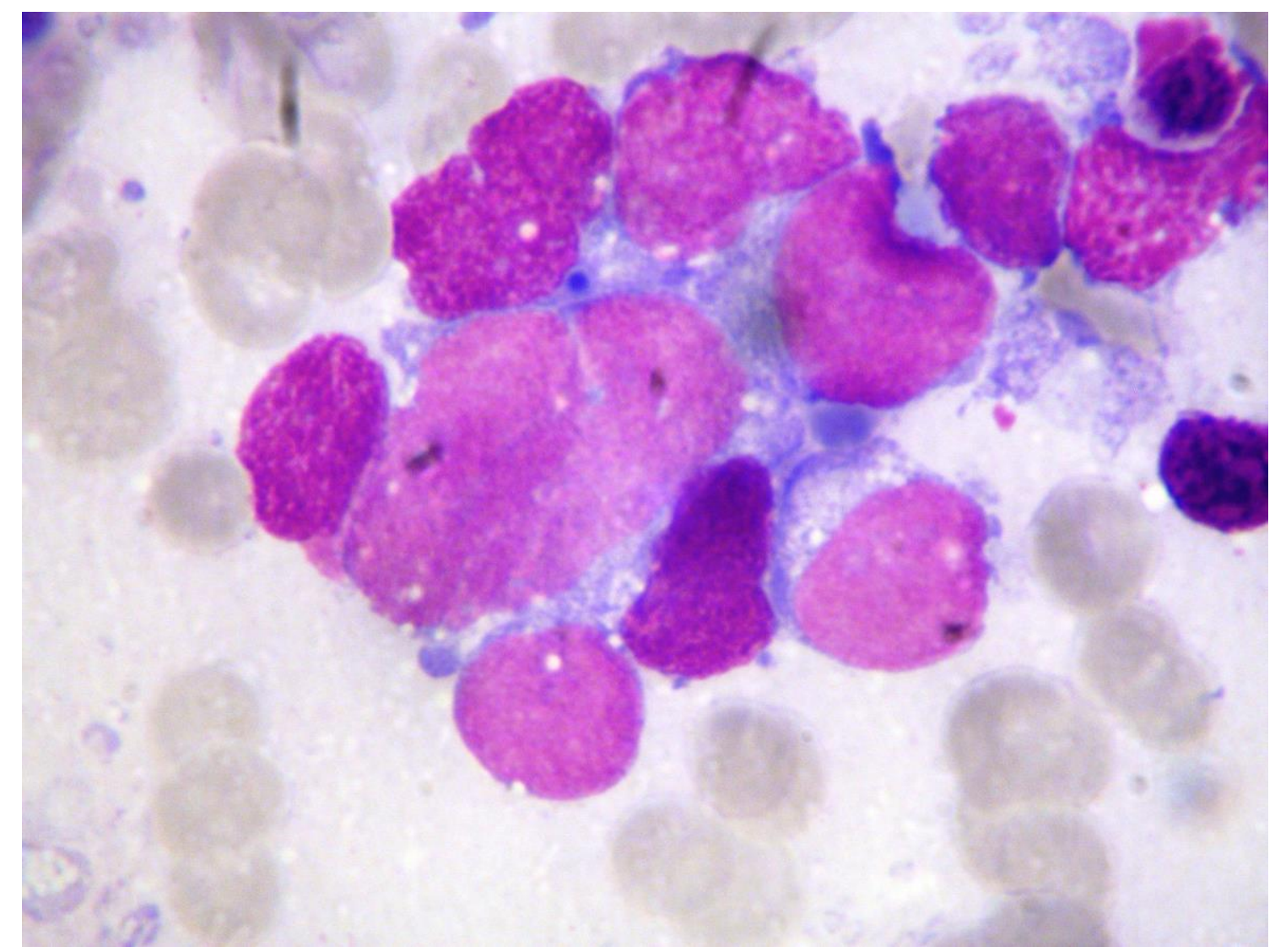

Abbildung 1: SCLC aus EBUS-TBNA, May-Grünwald-Färbung (Präparat der Lungenfachklinik Immenhausen, freundlicherweise überlassen von Dr. Rittmeyer) 


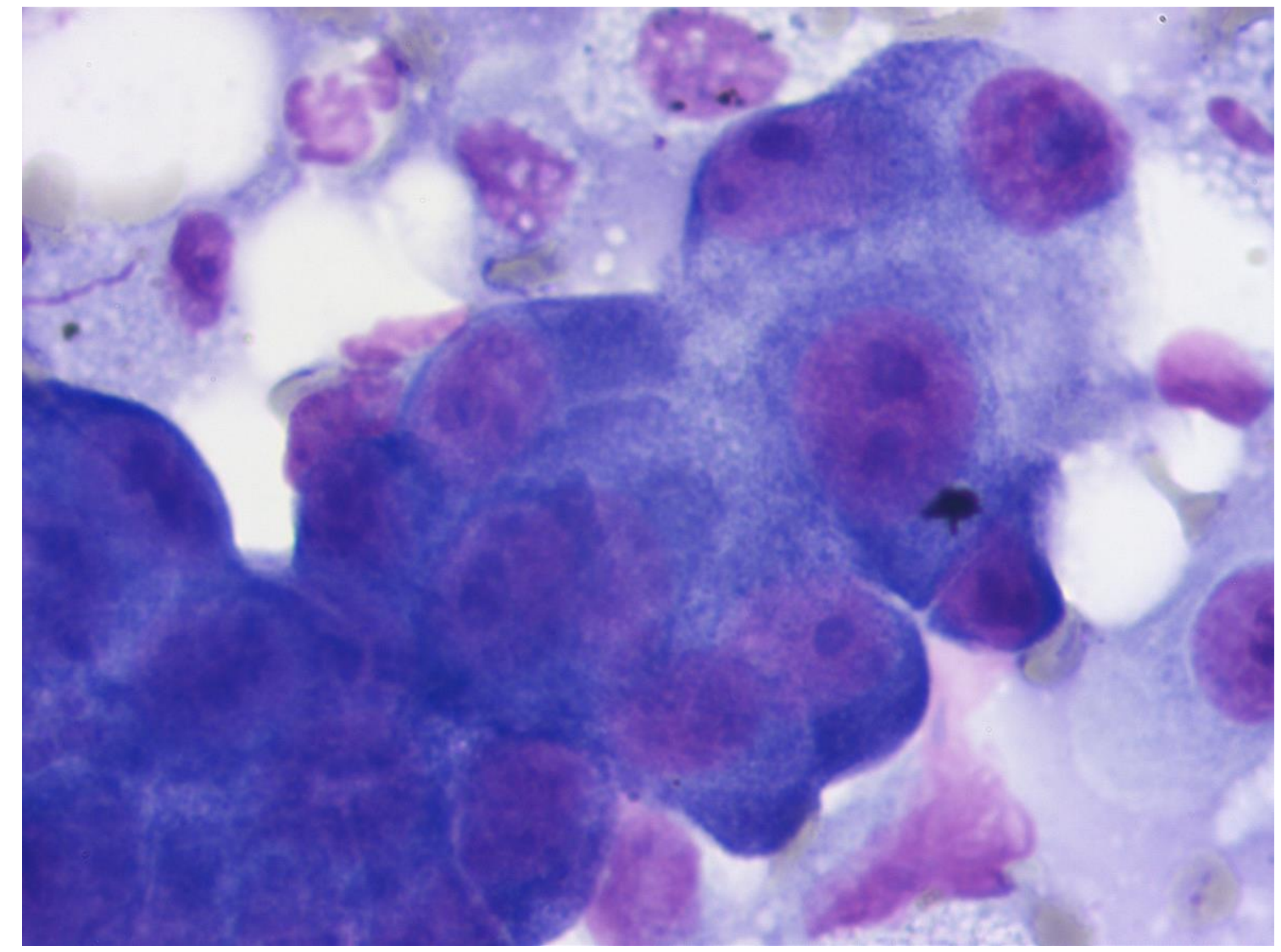

Abbildung 2: Adenocarcinom aus EBUS-TBNA, May-Grünwald-Färbung (Präparat der Lungenfachklinik Immenhausen, freundlicherweise überlassen von Dr. Rittmeyer)

Zytologisches Material hingegen kann, weniger invasiv gewonnen werden. Nadelaspirationen bieten im Gegensatz zu Inzisionsbiopsien auch den Vorteil, dass sie tiefer in das Tumorgewebe eindringen und so öfter repräsentatives Material zu Tage fördern können als Schnitt-und Zangenbiopsien, die eher an der Tumorkapsel oder Tumorpseudokapsel aus verdrängtem Ursprungsgewebe stattfinden. Das bekannteste Einsatzgebiet der Cytologie sind die PAP-Abstriche zur Cervixkarzinomprävention. Auch Zellen aus Körperflüssigkeiten können primär nur zytologisch begutachtet werden. 


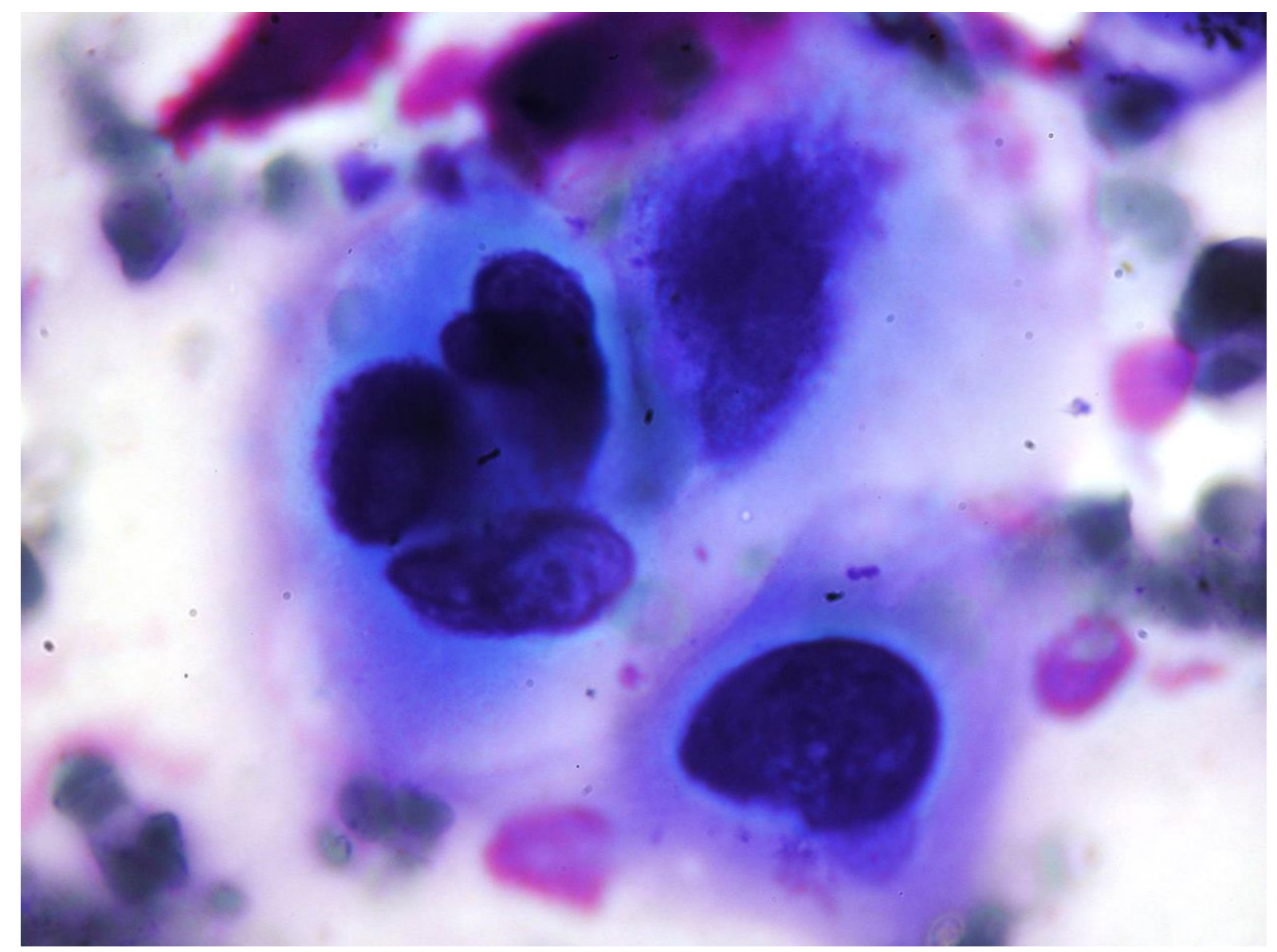

Abbildung 3: verhornendes Plattenepithelkarzinom aus EBUS-TBNA, May-Grünwald-Färbung (Präparat der Lungenfachklinik Immenhausen, freundlicherweise überlassen von Dr. Rittmeyer)

Während bei histologischen Präparaten beinahe beliebig viele Schnitte aus dem in Paraffin eingebetteten Geweben gewonnen werden können, ist das Material beim zytologischen Ausstrich sehr begrenzt. Aus der hauchdünnen Schicht von auf Objektträgern ausgestrichenen Zellen müssen die Suspekten gesucht und genau betrachtet werden. Eine Methode, um zytologischem Material weitere Aussagen abzugewinnen besteht darin, die sogenannte Cytoscrape-Technik anzuwenden. Das diagnostisch ausgewertete Objektträgermaterial wird dabei recycelt. Mit einem Skalpell wird das getrocknete, gefärbte Material vorsichtig von dem Objektträger gekratzt und in einer Zentrifuge mit Zusätzen zu einem Pellet zusammengepresst. So werden weitere Färbemethoden möglich, wie z.B. mit Immunmarkern. So können weitere Aussagen, wie etwa eine genauere Differenzierung zwischen NSCLC-Subtypen, getroffen werden (Skov et al. 2009). 


\subsection{Die Rolle des Pneumologen in der Behandlung von Lungenkrebs}

Pneumologen sind zunächst als effektive Anleiter von Rauchstopp-Programmen entscheidend an der Prävention beteiligt. Weiter spielen sie eine Schlüsselrolle in der Diagnose, dem Staging und der Behandlung von Patienten mit Lungenkrebs. Dabei wird eng mit Thoraxchirurgen, Onkologen, Radiologen und Palliativmedizinern zusammengearbeitet. Bei der Behandlung von Lungenkrebs haben sie oft eine zentrale Rolle, wenn es um die Erstellung und Durchführung eines Therapieplanes geht. Insbesondere sind sie an der Interpretation von radiologischen Befunden, der Durchführung von Interventionen wie Bronchoskopie und EBUS, Pleurapunktionen und der internistischer Thorakoskopie beteiligt. Die Gewebegewinnung ist für die Diagnosestellung, Staging, targeted Therapie und personalisierte Behandlung essentiell. Pneumologen sollten mit molekularen Testverfahren, und diagnostischen Prozeduren, wie EBUS und transthorakalen Biopsien vertraut sein, um die ausreichende Probengewinnung für immunhistologische und molekularbiologischen Testungen sicherzustellen. Weiter sind sie ausgebildet in der Behandlung von Komorbiditäten wie Dyspnoe, Ateminsuffizienz und Nebenwirkungen der Chemotherapie. Ihre Bedeutung bei Studien zur Einführung neuer Medikamente wächst (Gaga et al. 2013). Tatsächlich legen vergleichende Untersuchungen nahe, dass das Mitwirken eines Pneumologen im Behandlungsteam von Patienten mit Lungenkrebs den Behandlungserfolg verbessert (Fergusson et al. 2003).

\subsection{Zielsetzung der Studie}

Die in der Lungenfachklinik Immenhausen entnommenen diagnostischen TBNA-Proben werden seit vielen Jahren zur externen Befundung an das zytologische Labor Großhansdorf geschickt. Dort wird das Material von dem hauptberuflichen Zytopathologen Dr. Welker (LW) befundet, der jährlich ca. 15000 zytologische Präparate aus den Atemwegen beurteilt. Erfahrungsgemäß kommt es bei extern bewerteten Proben trotz guter Logistik zu Verzögerungen zwischen Entnahme- und Befundungsdatum. Zusätzlich werden daher seit Jahren die Zytologien vor dem Versand noch am Entnahmetag im hausinternen zytologischen Labor Immenhausen von zwei Fachärzten für Pneumologie befundet.

Da die primäre diagnostische und therapeutische Entscheidung oft von den mediastinalen Lymphknotenbefunden abhängt ist, sind verlässliche zytologische Befunde unverzichtbar. 
Allerdings wurde die Verlässlichkeit von zytologischen Befunden bisher nur in wenigen kleinen prospektiven Studien untersucht (Bonifazi et al. 2014; Skov et al. 2007; Steinfort et al. 2012). Z.B. ist die diagnostische Genauigkeit von zytomorphologischen Befunden von der Erfahrung der Untersucher abhängig (Skov et al. 2007). Ebenso ist bekannt dass prospektive Studien in diesem Setting Limitationen haben, da in ebensolchen Studien alle Beteiligten wissentlich unter Beobachtung stehen und sich typischerweise anders verhalten als ohne „Überwachung“ des eigenen Handelns (Hawthorne-Effekt).

In einer retrospektiven Studie zur Interobserver Reliabilität wollen wir daher überprüfen, ob ein hauptberuflicher Zytopathologe mit langjähriger Berufserfahrung bei identischem Untersuchungsmaterial zu den gleichen Ergebnissen kommt, wie zwei in der zytologischen Mikroskopie ausgebildete Pneumologen. Dabei stammen die Daten aus dem klinischen Alltag und stehen repräsentativ für das Behandlungskollektiv einer Lungenfachklinik.

\section{Material und Methoden}

\subsection{Material}

Die zu vergleichenden Untersucher sind das zytologische Labor Großhansdorf mit PD Dr. med. Welker (LW), hauptberuflicher Zytopathologe an der LungenClinic Großhansdorf und das zytologische Labor Immenhausen mit Dr. med. Achim Rittmeyer und Dr. med. Birgit Zwerger, beide Lungenfachärzte und Oberärzte an der Lungenfachklinik Immenhausen. Dr. Welker hat 35 Jahre Erfahrung mit Lungenzytologien, arbeitet ausschließlich als pneumologischer Zytolopathologe und befundet jährlich rund 15000 Lungenzytologien. Das zytologische Labor Immenhausen kommt auf etwa 1000 befundete Präparate im Jahr. Mit einem Arbeitsaufwand von ca. einer Stunde täglich werden die Befunde von beiden Oberärzten aus Immenhausen seit 4 (BZ) bzw. 10 (AR) Jahren (Stand 2012) befundet.

In beiden zytologischen Laboren wurden identische zytologische TBNA-Ausstriche aus dem Patientenkollektiv, das von 1. Januar 2012 bis 31. Dezember 2013 mit nachgewiesenem oder vermutetem Lungenkrebs in das Lungenfachklinikum Immenhausen zur Tumordiagnostik überwiesen wurde, untersucht. Dort wurde entweder ein leitliniengerechtes Staging oder ein Tumorausschlussverfahren durchgeführt. Die 
behandelnden Ärzte sind allesamt mit den Techniken der Bronchoskopie zur Materialgewinnung vertraut und werden kontinuierlich fortgebildet, bzw. werden unter Aufsicht in diesen Techniken ausgebildet. Für die Datenauswertung interessant sind alle mit Nadeln punktierten pulmonalen Lymphknoten, unabhängig von der angewandten bronchoskopischen Technik. Die TBNA erfolgt nach den präinterventionell angefertigten CT-Bildern oder ultraschallgestützt. Für die einfache TBNA wurden verschiedene Videobronchoskope (Olympus BF 1T 180, BF $\mathrm{P}$ 180, BF 1TQ 180) und 18G Punktionsnadeln (Somatex Broncho-Cut Expert, Teltow, Germany) benutzt. Die TBNA Punktionstechnik ohne Ultraschall wurde von zwölf verschiedenen Ärzten als Teil deren fachärztlichen Weiterbildung durchgeführt. Für die EBUS-TBNA wurde ein EBUSBronchoskop mit konvexem Schallkopf (BF-UC180F; Olympus, Tokyo, Japan) mit 22G Nadeln (NA-201SX-4022; Olympus) benutzt. Die EBUS-TBNA wurde ausschließlich von fünf erfahrenen Fachärzten durchgeführt. Die Bronchoskopie wurde unter Sedierung mit Midazolam und Propofol und Lokalanästhesie durchgeführt. Die so gewonnenen Feinnadelaspirate werden auf beschrifteten Objektträgern luftgetrocknet und im hauseigenen Labor nach May-Grünwald Giemsa angefärbt. Im Durchschnitt werden zwischen 3 und 5 Proben pro Patient und Sitzung entnommen. Die punktierten Lymphknoten werden entsprechend der „International Association for the Study of Lung Cancer lymph node map“ bezeichnet (Rusch et al. 2009).

Die fertigen Objektträger werden dann mit Anforderungsbogen für das zytologische Labor Großhansdorf versehen und im Zytolabor Immenhausen meist noch am Entnahmetag befundet. Dabei werden Objektträger aussortiert, auf denen kein Material oder fehlerhafte Färbungen zu sehen sind. Wenn klinisch kein Verdacht auf ein Malignom besteht und beide Untersucher des Zytolabors Immenhausen der Meinung sind, dass keine Malignität vorliegt wird nicht versandt. Die erhobenen Befunde werden als schriftlicher Befund in der Patientenakte dokumentiert und in eine Excel-Tabelle eingetragen. Danach gehen die Objektträger zur externen Befunderhebung nach Großhansdorf zu PD Dr. Welker, der keine Informationen über die Befundergebnisse aus dem Zytolabor Immenhausen erhält. 


\subsection{Methoden}

Im folgenden Flowchart eine Übersicht über das Vorgehen bei der Datenaufarbeitung.

\section{Datenaufbereitung}

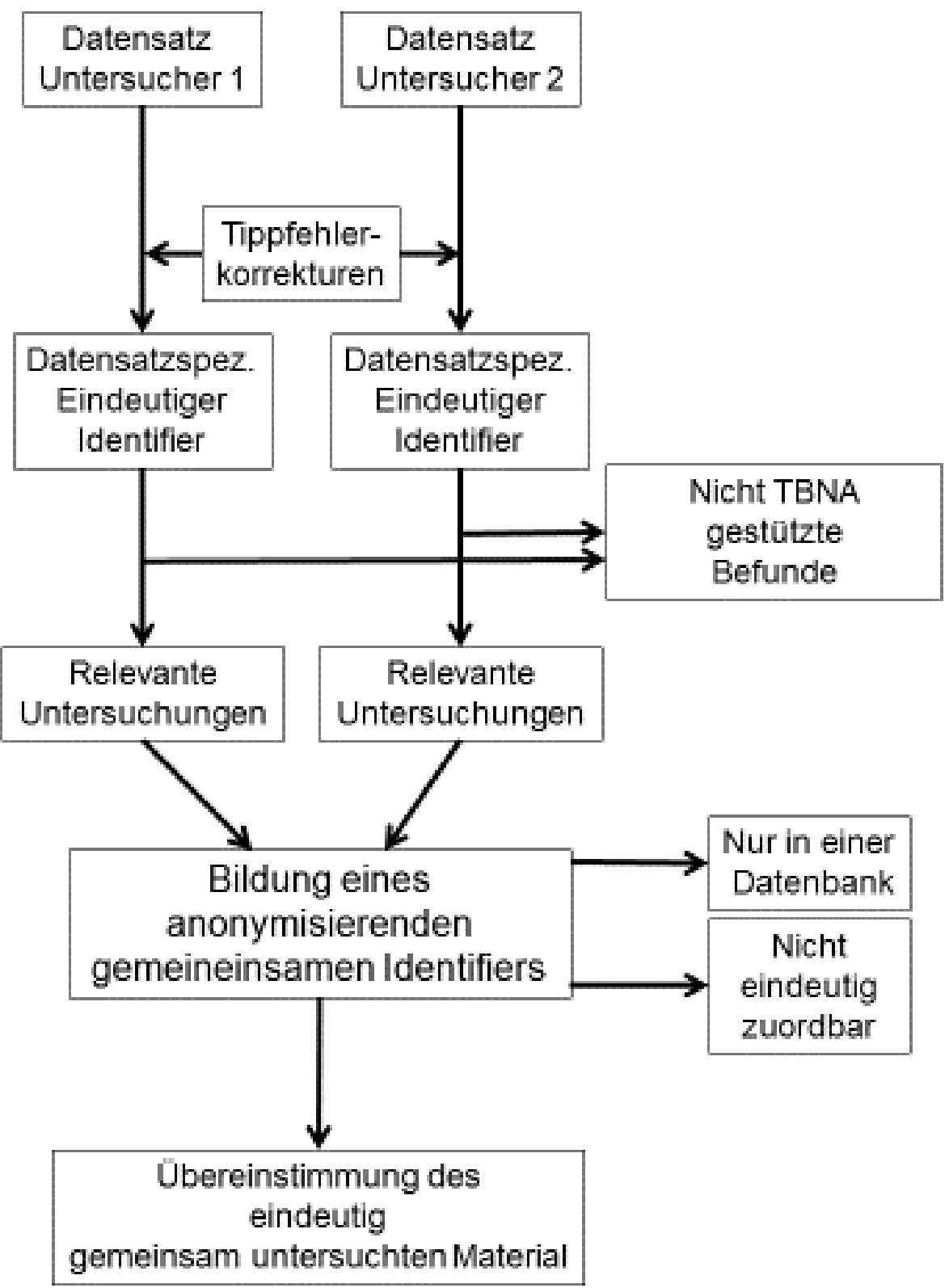


Initial fand die Datenbankabfrage in Großhansdorf statt. Alle Proben aus Immenhausen, die in den Jahren 2012 und 2013 eingingen, wurden abgefragt und in eine Excel-Tabelle konvertiert. Diese wurden mit dem durch das Zytolabor Immenhausen in einer ExcelTabelle eingegebenen Datensatz zusammengeführt. Anhand von Entnahmeort, Entnahmezeitpunkt und Art der Materialentnahme konnten Tippfehler in beiden Datensätzen gefunden und in jedem Datensatz einzeln korrigiert werden.

Anschließend wurden beide Datensätze nach relevanten Untersuchungsmethoden gefiltert. Dazu gehören: TBNA, EBUS, FNA (Feinnadelaspiration), FNP (Feinnadelpunktion). Ausgeschlossen wurden: Jede Form von Kathetersaugbiopsie, jede Form von Bürstung oder Imprint-Material, sowie einzelne Fälle von Knochenmarksbiopsien, Aszites und Pleuraerguss- oder Pericardergusspunktionen. Ein datensatzspezifischer Identifier wurde kreiert nach dem Muster: „Mustermann_Max_4L_41457_1““ (Name_Vorname_Entnahmeort_Entnahmedatum_Anzahl), der dann in einen anonymisierenden Nummerncode übersetzt wurde.

Nach der Aufbereitung und Zuordnung der Datensätze wurde der Entscheidungsbaum mit vier Entscheidungsstufen, die sukzessive aufeinander aufbauen für die statistische Auswertung genutzt. (siehe Abbildung 5) 


\section{Entscheidungsbaum}

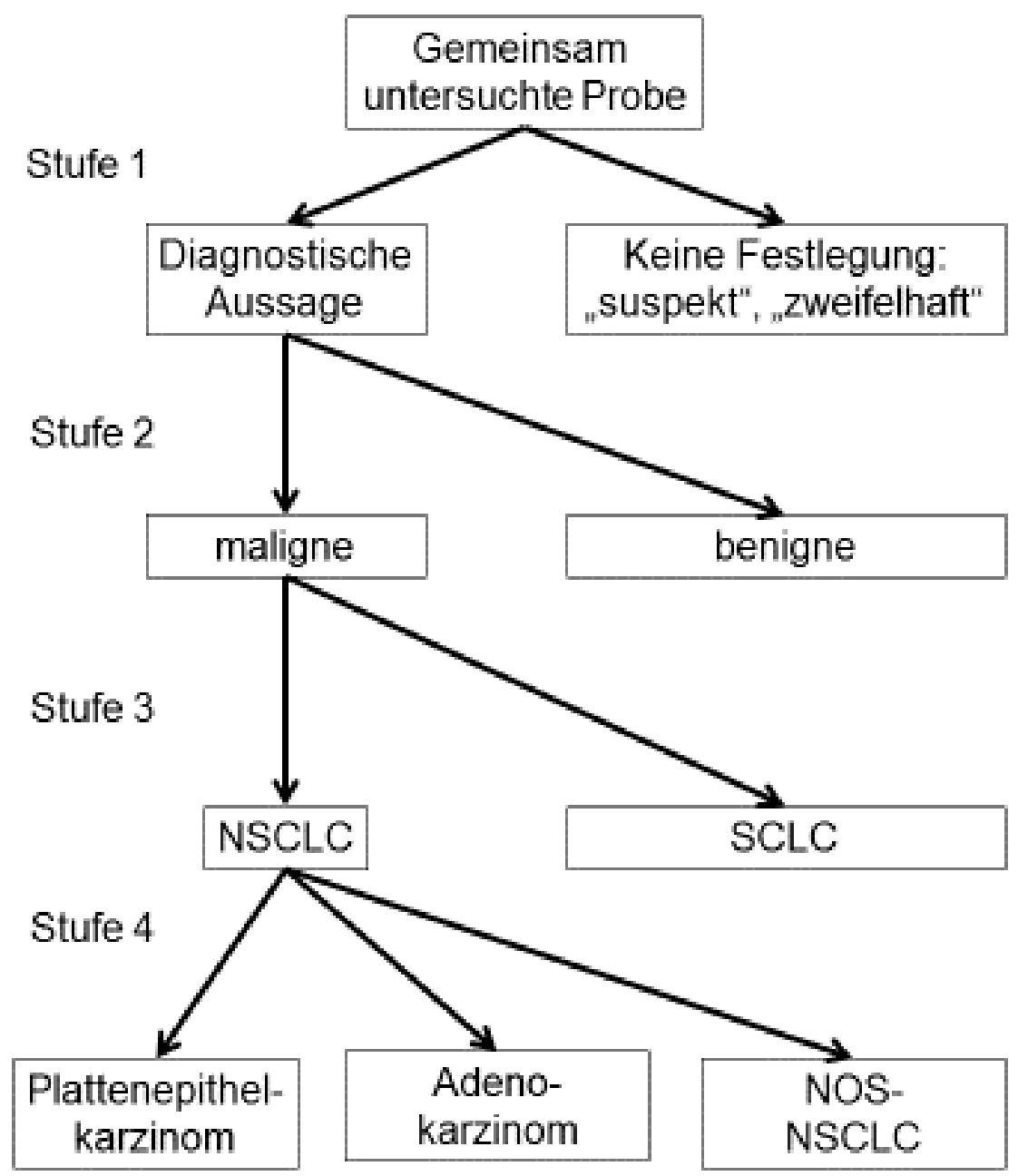

Abbildung 5: Entscheidungsstufen der zytologischen Untersuchung 
Entscheidungsstufe 1

Im ersten Schritt wird festgestellt, ob sich beide Untersucher auf eine diagnostische Aussage festlegen oder nicht. Die Ergebnisse wurden mit den Entscheidungen für Maligne oder Benigne in einer Tabelle ausgewertet und danach von der weiteren Betrachtung ausgeschlossen.

Entscheidungsstufe 2

Im zweiten Schritt wird die Übereinstimmung bei malignen und benignen Befunden überprüft. Falls nur bei einem Untersucher benigne, oder übereinstimmend benigne entschieden wurde, wurden auch diese Datenpärchen von der weiteren Auswertung ausgeschlossen. Nur die übereinstimmend als maligne gekennzeichneten Datensätze gingen in die nächste Entscheidungsstufe über.

Entscheidungsstufe 3

Im dritten Schritt wird die Übereinstimmung in den übergeordneten Kategorien NSCLC und SCLC getestet. Hier entfallen alle Datensätze, in denen von mindestens einem Untersucher SCLC oder ein anderer Tumor gesehen wurde. Nur die gemeinsam als NSCLC betitelten Befunde gingen in die letzte Entscheidungsstufe.

Entscheidungsstufe 4

Im vierten Schritt wird die Übereinstimmung in den häufigsten nicht-kleinzelligen Lungenkrebsentitäten gemessen.

Der Probenumfang verringerte sich mit jeder Aufteilung des Entscheidungsbaumes. In der Entscheidungsstufe zwei (maligne vs. benigne) konnte eine Annäherung an die Untersucherspezifische Sensitivität und Spezifität durchgeführt werden. Für diese Berechnungen ist ein Goldstandard notwendig, der tatsächlich vorliegende Krankheit oder Gesundheit definiert. Der Goldstandard ist die Histologie und ist bei einem Subkollektiv der untersuchten Gruppe vorhanden.

Dieses Subkollektiv wurde folgendermaßen definiert:

In Immenhausen wurde die Liste der im Tumorboard besprochenen Patienten als Grundlage genommen: die LTZ-Liste. Aus dieser wurden die Patienten, bei denen ein pTpN-Stadium vorlag, isoliert. Daraufhin wurden die Patientendaten in das zuvor beschriebene System der eindeutigen Identifikatoren (Name_Vorname_Entnahmedatum) 
übersetzt, dann mit den untersuchten Proben gematcht und die Zuordnung zu dem anonymisierenden Zahlencode durchgeführt. Es gab natürlich häufig mehrere Proben zu einem Patienten. Die Stellen, bei denen bei der programmierten Computerzuordnung doppelte Zuordnungen $\mathrm{zu}$ Proben zustande kamen, wurden einzeln überprüft und korrigiert, so dass jede in Frage kommende Probe auch einem histologischen Ergebnis zugeordnet werden konnte. Die histologischen Ergebnisse wurden vom Sekretariat der Thorax-Herz-Gefäßchirurgie Göttingen angefordert. Konsequenterweise wurden nur die Fälle ausgewertet, die von beiden Untersuchern ausgewertet wurden, also die Fälle mit eindeutigem Identifier.

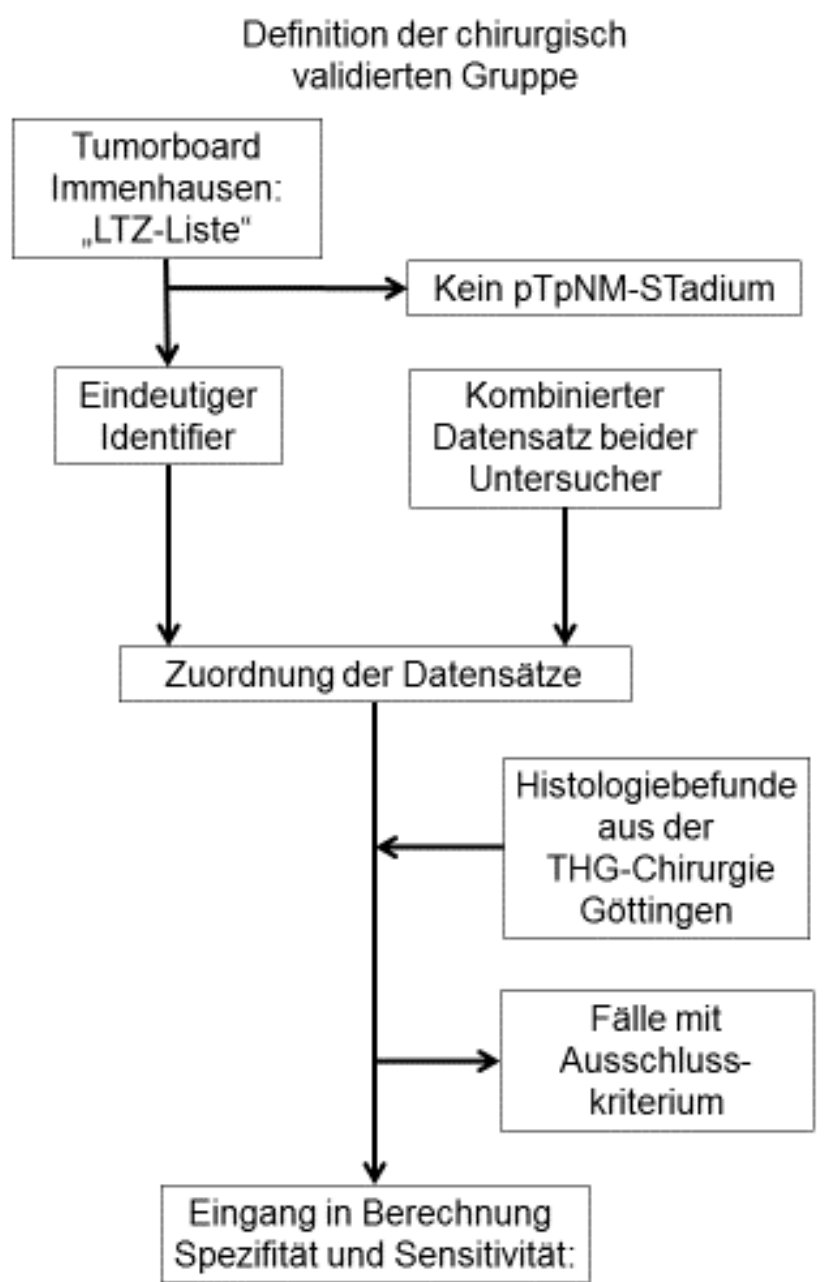

Abbildung 6: Definition der Gruppe mit chirurgischer Validierung 
Es wurden also alle im Tumorboard Immenhausen besprochenen OP-Kandidaten mit histologischem Befund, von denen TBNA-Befundergebnisse beider Untersucher vorlagen, herausgefiltert und in den bestehenden Datensatz eingegliedert.

Ausschlusskriterien:

1. Keinen Eingang in die Liste fanden die Daten der Patienten, bei denen eine neoadjuvante Radiochemotherapie durchgeführt wurde, da hier das pN-Stadium durch die Vorbehandlung nicht mehr dem bronchoskopisch untersuchten NStadium entspricht.

2. Auch bei den nicht routinemäßig untersuchten N1-Lymphknotenstationen galt für unsere Untersuchung ein Ausschluss wegen der zu geringen Anzahl und dem damit einhergehenden Verzerrungsrisiko. Auch die Trefferquote bei Durchführung der TBNA und die Genauigkeit der Pathologieberichte haben eine schlechtere Qualität als bei den routinemäßig durchgeführten N2-Lymphknoten.

3. Die Fälle, in denen nur von einem Untersucher eindeutig zuzuordnende zytologische Ergebnisse vorlagen, wurden konsequenterweise ebenfalls ausgeschlossen. 


\subsection{Statistische Auswertung}

Der Kappa-Wert, wie von Jacob Cohen vorgeschlagen (Cohen 1960), ist eine häufig genutzte Methode um die Übereinstimmung bei nominalskalierten Untersuchungsergebnissen zu evaluieren. Sie kann sowohl den Grad an Übereinstimmung, als auch den Grad an Nicht-Übereinstimmung oder Abweichung beziffern.

Primär wurden Tabellen erzeugt, mit denen Die Übereinstimmung quantitativ dargestellt wurde.

\begin{tabular}{|l|l|l|l|}
\hline & $\begin{array}{l}\text { Untersucher 2 } \\
\text { positiv }\end{array}$ & $\begin{array}{l}\text { Untersucher 2 } \\
\text { negativ }\end{array}$ & Summe \\
\hline $\begin{array}{l}\text { Untersucher 1 } \\
\text { positiv }\end{array}$ & a & b & $\mathrm{a}+\mathrm{b}$ \\
\hline $\begin{array}{l}\text { Untersucher 1 } \\
\text { negativ }\end{array}$ & $\mathrm{c}$ & $\mathrm{d}$ & $\mathrm{c}+\mathrm{d}$ \\
\hline Summe & $\mathrm{a}+\mathrm{c}$ & $\mathrm{b}+\mathrm{d}$ & $\mathrm{n}=\mathrm{a}+\mathrm{b}+\mathrm{c}+\mathrm{d}$ \\
\hline
\end{tabular}

Tabelle 1: Tabellenvorlage für die Übereinstimmungsberechnung

Darauf basierend wurden die Berechnungen für Cohens Kappa durchgeführt. Die Berechnungsformel lautet:

$$
\begin{gathered}
\mathcal{\varkappa}=\frac{p_{0}-p_{c}}{1-p_{c}} \\
\kappa=\text { Cohens Kappa } \\
p_{0}=\frac{(a+d)}{n} \\
p_{0}=\text { gemessener Übereinstimmungswert beider Untersucher } \\
p_{c}=\frac{\left(\frac{f_{1} \times g_{1}}{n}\right)+\left(\frac{f_{2} \times g_{2}}{n}\right)}{n} \\
p_{c}=\text { zufällige erwartete Übereinstimmung }
\end{gathered}
$$


Der Cohens Kappa Koeffizient wurde gemäß dem Vorgehen von Sim and Wright (Sim and Wright 2005) mittels Excel-Tabelle (Microsoft, Redmond, Washington, USA) berechnet. Das Ausmaß der Übereinstimmung wurde wie von Landis und Koch vorgeschlagen eingeteilt (Landis and Koch 1977):

\begin{tabular}{|l|l|}
\hline Kappa-Wert & Übereinstimmung \\
\hline $0-0,1$ & schlecht (poor) \\
\hline $0,1-0,21$ & etwas (slight) \\
\hline $0,21-0,40$ & ausreichend (fair) \\
\hline $0,41-0,60$ & mittelmäßig (moderat) \\
\hline $0,61-0,80$ & beachtlich (substantial) \\
\hline $0,81-1,0$ & vollkommen (almost perfect) \\
\hline
\end{tabular}

Tabelle 2: Kappa-Werte nach Landis und Koch

Weiter verwendeten wir das von der Universität Göttingen als Sammellizenz erworbene Programm STATISTICA 12.0 for Windows (StatSoft ,Hamburg, Germany), um VierFelder-Tafeln zu den einzelnen Entscheidungenstufen zu erzeugen, den p-Wert zu ermitteln und um Konfidenzintervalle zu bilden.

Für die chirurgisch validierte Subgruppe wurden Sensitivität und Spezifität für beide Labore berechnet. Sensitivität und Spezifität beurteilen die Güte eines Klassifikators (wie beispielsweise eines Tests oder wie im vorliegenden Fall eines Zytolabors). Sie sind die grundlegenden Effizienzmaße eines diagnostischen Tests (Altman and Bland 1994) und folgen einer Wahrscheinlichkeitsberechnung auf Grundlage der relativen Häufigkeit. Der Klassifikator muss dafür eine binäre Struktur haben, d.h. jeder gezählte Fall darf nur in einer Kategorie gezählt werden und darf nur zwei Merkmalsausprägungen (ja/nein oder richtig/falsch) haben (Bender 2001). In unserem Fall spiegelt die Histologie den wahren Zustand wider und die vom Zytolabor festgelegte Zytologie den Klassifikator (oder diagnostischen Test). 


\begin{tabular}{|l|l|l|l|}
\hline & Histologie (+) & Histologie (-) & \\
\hline Untersucher (+) & RP & FP & RP+FP \\
\hline Untersucher (-) & FN & RN & FN+RN \\
\hline & RP+FN & FP+RN & RP+FP+FN+RN \\
\hline
\end{tabular}

Sensitivität ist definiert als die Wahrscheinlichkeit mit der ein positives Testergebnis $(\mathrm{T}+)$ bei einer erkrankten Person $(\mathrm{K}+)$ auftritt oder in unserem Fall, die Wahrscheinlichkeit, mit der beispielsweise eine als maligne befundete Zytologie in Histologie ebenfalls einen malignen Befund hat

$$
\text { Sensitivität }=P\left(T_{+} / K_{+}\right)=\frac{P\left(T_{+} \cap K_{+}\right)}{P\left(K_{+}\right)}=\frac{R P}{R P+F N}
$$

Spezifität ist definiert als die Wahrscheinlichkeit, mit der ein negatives Testergebnis (T-) bei einer gesunden Person (K-) auftritt, oder in unserem Fall; die Wahrscheinlichkeit, mit der eine unauffällige Zytologie einen unauffälligen histologischen Befund hat.

$$
\text { Spezifität }=P\left(T_{-} / K_{-}\right)=\frac{P\left(T_{-} \cap K_{-}\right)}{P\left(K_{-}\right)}=\frac{R N}{F P+R N}
$$

\subsection{Ethik}

Die Ethikkommission Göttingen wurde vor Beginn der Studie konsultiert, befand die Studie für nicht beratungspflichtig und hatte keine Einwände gegen die Durchführung der Studie (DOK_29_2014). Die Grundsätze des Datenschutzes wurden dem niedersächsischen Datenschutzgesetz entsprechend eingehalten.

Beim Aufenthalt in der Lungenfachklinik Immenhausen haben alle untersuchten Patienten in die allgemeinen Vertragsbedingungen eingewilligt, wonach personenbezogene Daten und Proben in anonymisierter Form für Forschungszwecke weitergegeben und ausgewertet werden dürfen. 


\section{Ergebnisse}

Eine Übersicht über die Datenverarbeitung und den jeweiligen Probenumfang ist in den folgenden Abbildungen 7 und 8 dargestellt:

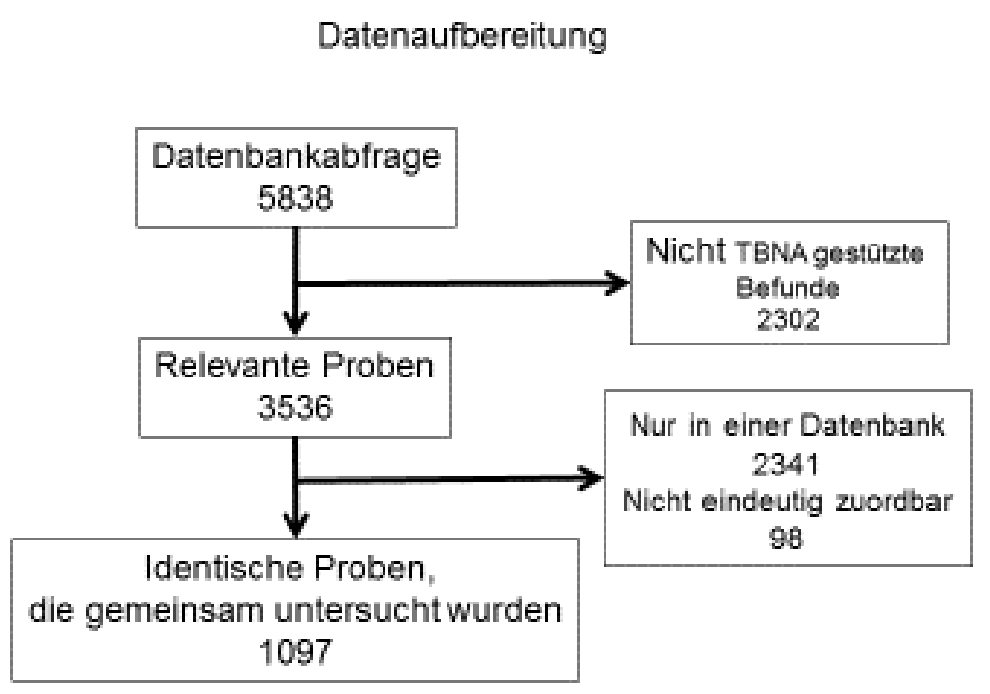

Abbildung 7: Ergebnis Datenaufbereitung

Von insgesamt 5838 Befunden, die sich aus Daten von beiden Untersuchern zusammensetzten (4071 aus dem Zytolabor Immenhausen und 1767 von Dr. Welker), waren 2302 Daten nicht TBNA gestützte Befunde (1609 aus dem Zytolabor Immenhausen und 571 von Dr. Welker). Nicht in die Auswertung eingegangen sind immunhistochemische Färbungen, die ungefärbt verschickt werden müssen und nicht in Immenhausen durchgeführt werden können, Urlaube der einzelnen Untersucher und nicht zur weiteren Überprüfung geschicktes Material, wie Material aus Pleuraergüssen, Ascites und Ähnlichem.

Aus den Verbleibenden 3536 Daten (2396 aus dem Zytolabor Immenhausen und 1196 von Dr. Welker) wurden Datenpärchen gebildet, die sich auf dieselben Objektträger beziehen. Es konnten 1097 Datenpärchen eindeutig identifiziert werden. 2340 fanden sich nur in einer Datenbank und bei 98 konnten letzte Zweifel (meist durch Tippfehler und nicht eindeutige Dokumentation) nicht ausgeräumt werden. Sie wurden daher von der weiteren Betrachtung ausgeschlossen. 


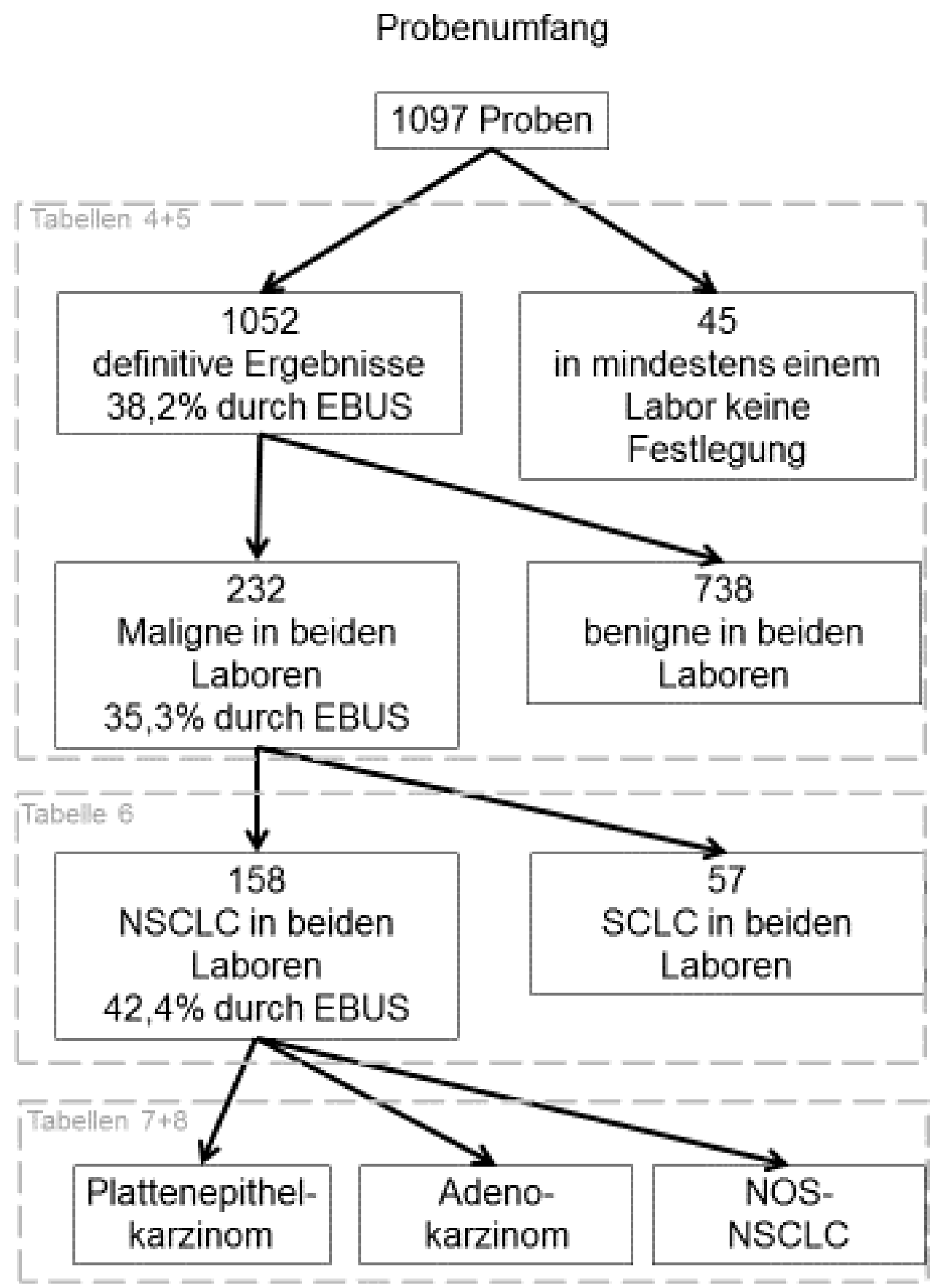

Abbildung 8: Probenumfang und Berechnungsgrundlage 
Die 1097 (von 828 verschiedenen Patienten) eindeutig mit einer Untersuchung identifizierbaren Datenpärchen wurden den ersten beiden Entscheidungsstufe (Maligne vs. Benigne vs. Suspekt) zugeführt. Bei 45 gemeinsam untersuchten Proben legte sich mindestens ein Untersucher nicht fest (27 Suspekte bei LKI, 17 bei L.W. und 1 bei beiden). Die Übereinstimmung lag bei $89 \%$ Prozent $(\kappa=0,72)$.

\begin{tabular}{|c|c|c|c|c|}
\hline & & \multicolumn{3}{|c|}{ L.W. } \\
\hline \multirow{2}{*}{} & $\mathrm{N}=1097$ & Maligne & Benigne & Suspekt \\
\hline & Maligne & 232 & 71 & 19 \\
\cline { 2 - 5 } & Benigne & 11 & 738 & 8 \\
\cline { 2 - 5 } & Suspekt & 3 & 14 & 1 \\
\hline
\end{tabular}

Tabelle 4: Vergleich der beiden Datensätze mit Fokus auf Malignität der Proben. Interobserver-Agreement: beachtlich/substantial ( $\kappa=0,72$, CI 0.69-0.75)

Suspekte Fälle beeinflussen die Therapieentscheidungen nicht, da bei solchen Ergebnissen die Untersuchung normalerweise wiederholt und diese somit geklärt werden. Die 45 Fälle, in denen mindestens ein Untersucher sich nicht festlegen konnte, wurden daher von der weiteren Betrachtung ausgeschlossen. 
Die 1052 Fälle (von 803 verschiedenen Patienten), in denen sich beide Untersucher festlegen konnten, wurden der zweiten Entscheidungsstufe, in der Malignität und Benignität gegenübergestellt werden zugeführt. Die Übereinstimmung stieg auf $92 \%$ $(\kappa=0.80$, CI 0.74-0.86).

\begin{tabular}{|c|c|c|c|}
\hline & & \multicolumn{2}{|c|}{ L.W. } \\
\hline & $\mathrm{N}=1052$ & maligne & benigne \\
\hline \multirow{2}{*}{ maligne } & benigne & 11 & 71 \\
\cline { 2 - 4 } & 23n & & 738 \\
\hline
\end{tabular}

Tabelle 5: Vergleich der beiden Datensätze mit Fokus auf Malignität der Proben. Interobserver-Agreement: beachtlich/substantial ( $\kappa=0.80$, CI 0.74-0.86)

In 21 Fällen lagen andere Krebsentitäten, wie Non-Hodgkin-Lymphome, Karzinoide, maligne Pleuramesotheliome und Metastasen von Mammakarzinomen, Colonkarzinomen oder Nierenzellkarzinomen vor. Diese wurden von der weiteren Betrachtung ausgeschlossen und reduzieren damit die Gesamtzahl auf 211 Proben (von 185 verschiedenen Patienten). 
Von den verbliebenen 211 übereinstimmend als maligne gekennzeichneten Proben wurde eine weiterführende Betrachtung in der dritten Entscheidungsstufe durchgeführt. Dabei wurde zwischen kleinzelligem Lungenkrebs (SCLC) und nicht-kleinzelligem Lungenkrebs (NSCLC) unterschieden. Die Übereinstimmung lag bei $96 \%$ ( $\kappa=0.89$, CI 0.76-1.03).

\begin{tabular}{|c|c|c|c|}
\hline \multirow{2}{*}{} & & \multicolumn{2}{|c|}{ L.W. } \\
\hline & $\mathrm{N}=211$ & SCLC & NSCLC \\
\hline \multirow{2}{*}{} & SCLC & 45 & 4 \\
\cline { 2 - 4 } & NSCLC & 4 & 158 \\
\hline
\end{tabular}

Tabelle 6: Vergleich der beiden Datensätze mit Fokus auf: SCLC vs. NSCLC. Interobserver-Agreement: vollkommen/almost perfect $(\kappa=0.89, \mathrm{CI} 0.76-1.03)$

Die acht Fälle, in denen sich die Labore nicht einig waren, wurden mit den korrespondierenden histologischen Ergebnissen desselben Patienten verglichen, die allerdings an anderer Stelle entnommen wurden, beispielsweise durch Zangenbiopsie am Primärtumor. Diese histologischen Ergebnisse führen dann $\mathrm{zu}$ den therapeutischen Entscheidungen im interdisziplinären Tumorboard und werden somit als definitive Diagnose betrachtet. Wenn man die so gewonnenen histologischen Ergebnisse als definitive Diagnose betrachtet, sind von den acht Fällen sechs durch das Zytolabor Immenhausen und zwei vom Zytolabor Großhansdorf richtig erkannt worden. 
In 158 Fällen (von 130 verschiedenen Patienten) konnten sich beide Untersucher auf NSCLC festlegen. Die NSCLC gliedern sich in die drei Entitäten: Plattenepithelkarzinom (PEC), Adenokarzinom (Adeno) und großzelliges Karzinom (NSCLC-NOS). Die Übereinstimmung lag bei $59 \%$ ( $\kappa=0.32$, CI 0.21-0.43).

\begin{tabular}{|c|c|c|c|c|}
\hline \multicolumn{2}{|c|}{} & \multicolumn{3}{|c|}{ L.W. } \\
\hline \multirow{4}{*}{} & N=158 & PEC & ADC & NOS \\
\hline \multirow{4}{*}{} & PEC & 18 & 0 & 0 \\
\cline { 2 - 5 } & ADC & 5 & 59 & 21 \\
\cline { 2 - 5 } & NOS & 14 & 25 & 16 \\
\hline
\end{tabular}

Tabelle 7: Vergleich der beiden Datensätze mit Fokus auf PEC vs ADC vs NOS. Interobserver-Agreement: ausreichend/fair ( $\kappa=0.32$, CI 0.21-0.43)

Aktuell ist im klinischen Alltag nur die Unterscheidung zwischen Plattenepithelkarzinom und Nicht-Plattenepithelkarzinom von Bedeutung. Die Adenokarzinome und NOS können zusammengefasst werden, was $\mathrm{zu}$ einer moderaten Übereinstimmung führt. Die Übereinstimmung liegt bei $88 \%(\kappa=0.59$, CI $0.45-0.74)$.

\begin{tabular}{|c|c|c|c|}
\hline \multicolumn{2}{|c|}{ N=158 } & \multicolumn{2}{c|}{ L.W. } \\
\cline { 2 - 4 } & PEC & Nicht-PEC \\
\hline \multirow{2}{*}{} & PEC & 18 & 0 \\
\cline { 2 - 4 } & Nicht-PEC & 19 & 121 \\
\hline
\end{tabular}

Tabelle 8: Vergleich der beiden Datensätze mit Fokus auf PEC vs. Nicht-PEC. Interobserver-Agreement: ausreichend/fair ( $\kappa=0.59$, CI 0.45-0.74) 
In einer Subgruppe war es möglich die zytologischen Ergebnisse mit postoperativ gewonnenen Histologien abzugleichen. Die Subgruppe definierte sich aus dem Anteil der untersuchten Kohorte, der einer Operation zugeführt wurde. Auf insgesamt 1097 auswertbare und von beiden Zytolaboren untersuchte Proben fallen 107 Operationen. Von den 107 Operationen ließen sich 96 eindeutig dem Datensatz zuordnen. Von den N=96 Fällen wird nur das bronchoskopische N2-Staging (typischerweise Lk-Stationen 4+7) betrachtet, da nur dies routinemäßig mit der TBNA erfasst wird. Es fallen daher weitere 11 operierte Patienten aus der Betrachtung $(\mathrm{N}=85)$. Weitere 9 mussten entfallen, da weder Operationsbericht, noch Pathologiebefund eine eindeutige Zuordnung zu den untersuchten Lymphknotenstationen zuließen (4 Fälle), oder weil der punktierte Lymphknoten bei der Operation (z.B. kontralateral hilärer LK) nicht mit entnommen wurde (5 Fälle; N=76). Da sich nach neoadjuvanter Radiatio das Nodalstadium verändern kann, wurden alle Fälle mit neoadjuvanter Radiatio ebenfalls aus der Betrachtung ausgeschlossen, um größtmögliche Sicherheit bei der Ortsdiagnose zu schaffen. So entfallen weitere 6 operierte Patienten $(\mathrm{N}=70)$. 


\section{Sensitivităt und Spezifität der chirurgisch validierten Subgruppe}

\begin{tabular}{|l|l|l|l|}
\hline & $\begin{array}{l}\text { Histologie } \\
\text { maligne }\end{array}$ & $\begin{array}{l}\text { Histologie } \\
\text { benigne }\end{array}$ & Gesamt \\
\hline $\begin{array}{l}\text { L.W. } \\
\text { maligne }\end{array}$ & 0 & 1 & 1 \\
\hline $\begin{array}{l}\text { L.W. } \\
\text { benigne }\end{array}$ & 1 & 68 & 69 \\
\hline Gesamt & 1 & 69 & 70 \\
\hline
\end{tabular}

Sensitivität $=0 / 1=0 \%$

Spezifität $=68 / 69=98,55 \%$

\begin{tabular}{|l|l|l|l|}
\hline & $\begin{array}{l}\text { Histologie } \\
\text { maligne }\end{array}$ & $\begin{array}{l}\text { Histologie } \\
\text { benigne }\end{array}$ & Gesamt \\
\hline $\begin{array}{l}\text { LKI } \\
\text { maligne }\end{array}$ & 1 & 7 & 8 \\
\hline $\begin{array}{l}\text { LKI } \\
\text { benigne }\end{array}$ & 0 & 62 & 62 \\
\hline Gesamt & 1 & 69 & 70 \\
\hline
\end{tabular}

Sensitivität $=1 / 1=100 \%$

Spezifität $=62 / 69=89,86 \%$ 


\section{Diskussion}

Die für den klinischen Entscheidungsprozess wichtigsten Parameter, nämlich der Nachweis von Malignität ( $92 \%$ Übereinstimmung =beachtlich/substantial agreement) und die Kategorisierung in NSCLC und SCLC (96\% Übereinstimmung =vollkommene/almost perfect agreement) erreichen im Vergleich beider Labore hohe Übereinstimmungen. Unseres Wissens nach ist dies mit über 1000 Proben von mehr als 800 verschiedenen Patienten die größte zytologische TBNA-Probenserie, die das Interobserver-Agreement zwischen einem Zytopathologen und zwei zytologisch ausgebildeten Pneumologen untersucht.

Die bisher größte Studie, in der zytologische Ergebnisse miteinander verglichen wurden, stammt von Bonifazi et al. Sie umfasst 362 TBNA-Ausstriche von 84 Patienten. In dieser Studie wurde die Performance eines fachärztlichen Zytopathologen (board-certified) mit der eines zytopathologisch nicht ausgebildeten Pneumologen verglichen. Letzterer erhielt unmittelbar vor der Studie ein dreimonatiges Training für die Bewertung zytologischer Ausstriche. Verglichen wurde anhand von ROSE-Ausstrichen (Rapid on-site evaluation), bei denen es primär um die Bewertung der Probenadäquatheit ging. In einem zweiten Schritt wurde zu einem späteren Zeitpunkt Probenmaterial aus gleicher Sitzung und gleicher Position in Normalfärbung in fünf zytologische Kategorien eingeteilt (maligne, eher maligne, eher benigne, benigne und nicht verwertbare Probe/nicht adäquat) und die Ergebnisse beider Untersucher miteinander verglichen. Für maligne/benigne wird bei Bonifazi eine Übereinstimmung von 92-93\% (K=0,69-0,81) erreicht. Unsere Übereinstimmung liegt bei vergleichbaren $0,92 \%(K=0,80)$.Unsere Werte sind durch die vielfach höhere Fallzahl (1052 in der Entscheidungsstufe maligne vs. benigne) deutlich valider, und bestätigen die Werte von Bonifazi. Bei Bonifazi ist das Patientenkollektiv offensichtlich selektiert, da 64 von 84 (74\%) Patienten maligne Befunde hatten. Die Sensitivität der TBNA steigt bei mit der Prävalenz an Erkrankten (Dominicis et al. 2015). Bei isolierter mediastinaler Lymphadenopathie (IML) treten aber im Allgemeinen nur in 10-20\% der Fälle maligne Befunde auf (Evison et al. 2014; Navani et al. 2012). In unserer Studie weisen 232 Patienten (22\%) eine Malignität auf. Dies zeigt, dass unser Patientenkollektiv nicht vorselektiert wurde. Die bei uns immer noch geringfügig erhöhte Malignitätsrate bei IML ist auf das einschlägige Patientenkollektiv eines tertiären Versorgungszentrums der Lungenheilkunde zurückzuführen. 
In der Studie von Bonifazi wurde der Untersucher ohne zytolog. Vorbildung in einem Zeitraum von drei Monaten fortgebildet. In dieser Zeit nahm er an den wöchentlichen zytopathologischen Sitzungen teil, in denen jeweils 3 Stunden zytopathologische Diagnostik unter professioneller Anleitung stattfand. Ergänzend wurden im gleichen Zeitraum Bücher zur Weiterbildung genutzt. Die Studie zeigt, dass schon nach kurzer Ausbildungsdauer hohe Übereinstimmungen in der zytologischen Differenzierung zwischen maligne und benigne erreicht werden können. Kritisch ist anzumerken, dass eine Verblindung des untersuchenden Pneumologen gegenüber dem Patienten bei der Erstellung der ROSE-Ausstrichen nicht durchgeführt wurde.

Steinfort et al. führten eine weitere, wenn auch kleinere Studie durch, in der drei erfahrene (Minimum 10 Jahre Berufserfahrung) Fachärzte für Pathologie einzeln miteinander verglichen wurden. Es wurden TBNA-Proben von 60 verschiedenen Lungenkrebspatienten ausgewählt, bei denen die Übereinstimmungen der Kategorisierung in SCLC vs. NSCLC und die Subklassifizierung der NSCLC Befunde gemessen wurden. Dies wurde nacheinander für drei verschiedene histologische Fixierungs/Aufbereitungsmethoden getan. Im ersten Durchgang wurden zytologische Ausstriche bewertet, was zu einem Kappa-Wert von 0,70 für NSCLC vs. SCLC und 0,095 für die NSCLC-Subtypen führte. In einem zweiten Schritt wurde zytologisches Material, das aus der gleichen Entnahmeprozedur stammt, in Formalin fixiert, dann in Paraffin eingebettet, geschnitten und als „histologisches“ Präparat untersucht. Die Übereinstimmung stieg hierbei auf 0,81 für NSCLC vs. SCLC und auf 0,278 für die drei NSCLC-Subtypen. Im finalen Schritt wurden dann die mit histologischen Techniken aufgewerteten Proben mit Immunhistochemischen Markern versehen. Dabei stieg Kappa auf 1,0 für NSCLC vs. SCLC und auf 0,56 für die NSCLC Subtypisierung.

Obwohl das Zytolabor Immenhausen keinen Pathologen oder zertifizierten Untersucher beschäftigt, erreicht unsere Studie im Vergleich von NSCLC vs. SCLC einen Kappa-Wert von 0,89. Dieser liegt im Bereich der Werte der histologischen Aufarbeitungen, die bei Steinfort in beiden Entscheidungsstufen das Agreement erhöht hatten. Die Übereinstimmung der NSCLC-Subtypisierung liegt mit K=0,32 ebenfalls in beiden Fällen höher. Mittels Immunhistochemie lässt sich die Übereinstimmung, wie Steinforts Studie zeigt, nochmals deutlich erhöhen. Im Zytolabor Immenhausen gibt es ein solches Vorgehen nicht und somit auch keine Vergleichswerte. Es zeigt sich allerdings, dass die 
geübten Pneumologen beim einfach gefärbten Ausstrich im Vergleich zu den erfahrenen Pathologen sehr gute Ergebnisse erzielen.

In einer anderen Studie (Skov et al.) wurden vier erfahrene Fachärzte für Pathologie (15 Berufsjahre Minimum) mit unterschiedlicher Expertise im Bereich der pulmonalen Zytopathologie (von fast keiner Berufserfahrung bis zu 10 Jahren) 102 Präparate aus pulmonalen Lymphknoten zweimal zur Diagnoseeinordnung in 5 Kategorien (not suspicious, suspicious but not adäquat für Malignität, maligne-NOS, NSCLC, SCLC) geschickt. Zwischen beiden Runden wurde ein Seminar über Zytologische Entscheidungskriterien gehalten. Dabei stiegen die Kappawerte von 0,52-0,89 auf 0,650,87 .

Wegen der Zusammenfassung der ersten beiden Entscheidungsstufen und der Hinzunahme der Kategorie „not adequat for malignancy“ lässt sich für diese Studie kein genauer Vergleich ziehen. Allerdings liegen unsere Kappa-Werte (maligne vs. benigne $=0,80$ und NSCLC vs. SCLC $=0,89$ ) in beiden angewandten Entscheidungsstufen, die sich zumindest als Teilmenge mit den von Skov erzielten Werten vergleichen lassen, am oberen Ende der angegebenen Kappa-Werte-Spanne. Ein Hinweis darauf, dass unsere Ergebnisse mit denen erfahrener Pathologen vergleichbar sind.

In der täglichen Routine ist die Differenzierung zwischen den NSCLC-Subtypen für die definitive therapeutische Entscheidung bezüglich der Chemotherapie oder weiterführender molekularbiologischer Testung von großer Bedeutung. Für das Staging und die primäre Weichenstellung der Therapie in Richtung Operation, Radiatio oder alleiniger Chemotherapie ist die NSCLC-Subtypisierung weniger wichtig.

Nur drei Studien außer unserer untersuchten das Interobserver-Agreement in Bezug auf genau diese Fragestellung. Die Ergebnisse sind in Tabelle 10 aufgeführt. 


\begin{tabular}{|l|c|c|c|}
\hline & maligne vs. benigne & NSCLC vs. SCLC & NSCLC-Subtypen \\
\hline Bonifazi & $0.69-0.81$ & NA & NA \\
\hline Skov & $0.52-0.89$ & NA & NA \\
\hline Steinfort & NA & $0.70-0.81$ & $0.1-0.28$ \\
\hline eigene Werte & $0.72-0.80$ & 0.89 & $0.32-0.59$ \\
\hline
\end{tabular}

Tabelle 10: Kappa-Werte unserer Daten im Vergleich mit den drei anderen Studien, die Interobserver-Agreement für TBNA untersucht haben. Die Spannen der Kappa-Werte ergeben sich aus der verschiedenen Anzahl von Untersuchern und Kategorien in den einzelnen Studien. Im Vergleich dargelegt jeweils vorteilhafteste und unvorteilhafteste Vergleichsmöglichkeit der Ergebnisse. Dabei wurden jeweils vergleichbare Konditionen zu Grunde gelegt. $(N A=n o t$ available)

Es gibt weitere Studien, die die Überweinstimmung zwischen Histologie und Zytologie messen, wie beispielsweise die Studie von Nizzoli et al., die cytologische TBNAErgebnisse mit histologischen Ergebnissen aus Operationen oder endoskopischen Biopsien vergleicht. Er konnte ein Agreement von 0,76 zeigen. Es werden allerdings Gewebeproben aus unterschiedlichen anatomischen Regionen miteinander verglichen, weswegen diese Studie nicht als Interobserver-Reliabilitätsmessung angesehen werden kann (Nizzoli et al. 2011).

Viele Studien untersuchen die Interobserver Reliabilität von histologischen Proben. Beispielsweise haben Paech et al. ein systematisches Review des InterobserverAgreements im Hinblick auf die Differenzierung zwischen PEC und Nicht-PEC durchgeführt. Er identifizierte sechs Studien, die eingeschlossen werden konnten. Die Ergebnisse lagen zwischen 0,48-0,87. Diese Ergebnisse können nicht mit unseren Verglichen werden, da die histologischen Subtypen üblicherweise mit immunhistochemichen Markern bestimmt werden und nicht, wie in unserem Fall, nur anhand der Morphologie (Paech et al. 2011).

In unserer chirurgisch validierten Subgruppe wurde Wert darauf gelegt, dass die histologischen Korrelate die exakt gleichen Lymphknoten sind, die vorher mittels TBNA punktiert wurden. Somit konnten eindeutige Werte für die untersucherspezifische Sensitivität und Spezifität berechnet werden. Wir können nur die Spezifität betreffend eine Aussage treffen, da das operierte Kollektiv bei uns nach Vorliegen einer Histologie nach OP retrospektiv gefiltert wurde und somit der Anteil von histologisch verifizierten Gesunden (2 Fälle) nicht ausreichend ist. In der aktuellen Literatur finden sich Werte für die Spezifität der EBUS-TBNA von 93-100\% (Dominicis et al. 2015; Ernst et al. 2008; 
Um et al. 2015). Unsere Werte liegen mit 89,86 (LKI) und 98,55 (L.W.) im Bereich der üblichen Werte. Kritisch anzumerken ist, dass Sensitivität und Spezifität von der Prävalenz erkrankter Lymphknoten abhängig sind (Dominicis et al. 2015). Da in unserem Subkollektiv quasi alle in der TBNA benigne getesteten nicht histologisch verifiziert wurden und weil bei uns keine Vorselektion bei der Auswahl zu punktierender Patienten besteht können unsere Werte nicht die unter prospektiven Studienbedingungen erzielten Werte von Sensitivität und Spezifität erreichen. Weiter ist das operierte Kollektiv mit 70 Patienten relativ klein und lässt somit nur eine einordnende Aussage zu. Dennoch liegen unsere Ergebnisse trotz dieser Einschränkungen im Bereich der beschriebenen Spezifität ohne signifikante Abweichung.

Bei der Studie handelt es sich unseres Wissens nach um die größte Probenserie, die Interobserver-Agreement zwischen zwei Zytologielaboren an TBNA- und EBUS-TBNA gestützten zytologischen Ausstrichen untersucht. Weiter ist sie die bisher einzige retrospektive Studie, die versucht, den klinischen Alltag einer großen Thoraxklinik abzubilden. Da es sich um eine ,real-life“-Studie handelt, können die Ergebnisse besser auf den klinischen Alltag und andere Einrichtungen übertragen werden als Ergebnisse prospektiver Studien, in denen der Hawthorne Effekt zum Tragen kommt. Dieser beschreibt die Verbesserung von Testergebnissen, wenn die Studienteilnehmer wissen, dass sie unter Beobachtung stehen. Die Daten unserer Studie stehen beispielhaft für die tägliche Routine großer Lungenkrebszentren weltweit. Es werden Daten behandelt, die ursächlich für wichtige Therapieentscheidungen sind. Eine Kommunikation zwischen den untersuchenden Parteien gab es nicht.

Die verglichenen Zytolabore haben nicht den gleichen Ausbildungsstand. Das Zytolabor Großhansdorf ist mit 15000 Zytologien pro Jahr überregionales Referenzzentrum für zytologische Ausstriche, wohingegen das Zytolabor Immenhausen jährlich nur die etwa 1000 hauseigenen Ausstriche befundet. Aus dieser Erfahrungsdifferenz lässt sich - auch im Vergleich mit den anderen zitierten Studien - schließen, dass nach einigen Jahren Erfahrung offensichtlich eine zuverlässige cytologische Befundung von TBNA Ausstrichen möglich ist. Wann genau diese Kompetenz - im Sinne einer Lernkurve erreicht ist, ist eine andere Frage und muss gesondert untersucht werden. 
Limitationen

Da, wie im Kapitel „Material“ beschrieben, nicht alle Proben vom Zytolabor Immenhausen weitergeleitet wurden kann es zu einer Vorselektion und einem damit einhergehenden systematischen Fehler gekommen sein. Systematisch nicht verschickt wurden oft ganz eindeutig benigne Befunde, bei denen kein Malignitätsverdacht vorlag und sich beide Untersucher im Zytolabor Immenhausen ganz sicher waren. Auch nicht-diagnostische Punktionen wurden nicht verschickt. Durch die sinkende Fallzahl von ganz eindeutig benignen Befunden wird die Übereinstimmungsrate der beiden Untersucher eher systematisch verschlechtert, als verbessert.

Aus unseren Daten kann nicht geschlossen werden, welches Labor die richtigen Aussagen getroffen hat. Zwar gibt es für die meisten Proben histologisches Material, das die Diagnose stützt, allerdings meist nicht aus dem zu überprüfenden Lymphknoten, sondern aus anderen Strukturen, wie beispielsweise Zangenbiopsien aus dem Primärtumor. Diese spiegeln die Diagnose am Ort des punktierten Lymphknotens nicht wider. Nur der nach Operation histologisch untersuchte Lymphknoten, der vorher mittels TBNA punktiert wurde, konnte ausgewertet werden.

Die Ergebnisse der errechneten Sensitivität und Spezifität können nur einen tendenziellen Charakter haben. Aufgrund des Mangels an histologisch aufgearbeiteten Fällen und der Selektion im Subkollektiv hin zum gesunden N2-Status ist auch die Berechnung der Sensitivität verzerrt und somit nicht verwertbar. Der Vollständigkeit halber ist diese dennoch im Ergebnisteil aufgeführt. Die Spezifität hingegen als Rate richtig ausgeschlossener Befunde ist zwar auswertbar, allerdings durch die sehr geringe Fallzahl von 70 nur als Anhaltspunkt dafür zu werten, dass sich beide Untersucher im für die TBNA üblichen Spezifitätsbereich bewegen.

Da die Bronchoskopien mit TBNA von über zehn verschiedenen Untersuchern durchgeführt wurden, kann ein Cofounder durch eine systematisch fehlerhafte Probenentnahme weitgehend ausgeschlossen werden.

Schwächen an dem retrospektiven Modell ergeben sich durch die im Vergleich mit prospektiven Studien schlechtere Datenqualität. Diese ist der händischer Eingabe (viele Tippfehler) und der nicht genormten Dokumentation geschuldet. Die Aufarbeitung und die Zuordnung der Datensätze könnten einzelne Daten verfälscht haben. Die Regeln, die zum Abgleich genutzt wurden haben eher eine fragwürdige Probe ausgeschlossen, als dass sie 
das Ergebnis verzerrt haben. Dass durch den Ausschluss einiger Proben aufgrund dokumentatorischer Mängel ein systematischer Fehler entstehen kann ist daher unwahrscheinlich.

Man muss sich die Frage stellen, ob die Pneumologen durch den klinischen Eindruck, sowie die für sie einsehbare Bildgebung zu anderen Ergebnissen kommen, als der vom Klinikalltag isolierte Zytopathologe. Zwar stehen auf dem Befundanforderungsbogen die relevanten Daten, allerdings ist nicht klar, ob der verbleibende Wissensvorsprung zu einer besseren oder genaueren Einschätzung in egal welcher Entscheidungsstufe beiträgt. Dafür fehlte uns ein „flächendeckender“ Goldstandard. Unser Subkollektiv lässt eine solche Aussage nicht zu.

\section{Zusammenfassung:}

Die Beurteilung von Lymphknoten mittels TBNA ist eine therapieentscheidende Aufgabe bei Lungenkrebs. Bisher wurde diese Aufgabe von Spezialisten übernommen, meist Pathologen, die hauptberuflich Zytologien auswerten. In der Lungenfachklinik Immenhausen wurden die Proben vor Versand noch am Entnahmetag gefärbt und im hauseigenen Zytolabor von zwei in der Mikroskopie geübten Fachärzten für Pneumologie beurteilt. Die Übereinstimmung mit dem hauptberuflichen Zytopathologen wurde an 1052 Proben von 828 verschiedenen Patienten aus den Jahren 2012 und 2013 im Hinblick auf Malignität und Tumorentität bestimmt. In dieser „real-life“ Studie war das InterobserverAgreement zwischen geübten Pneumologen und einem erfahrenem Spezialisten für thorakale Zytologien fast vollkommen (,high“), insbesondere in der Unterscheidung zwischen malignen und benignen Befunden, sowie der Unterscheidung zwischen NSCLC und SCLC. Bei den NSCLC-Subtypen war die Übereinstimmung ausreichend (,fair"). Unsere Daten legen nahe, dass ausgebildete Pneumologen fähig sind zytologische Proben in der täglichen Routine sicher zu bewerten. Dies kann eine Verbesserung der Patientenversorgung bedeuten, da eine ortsansässige Zytologie schnelle Ergebnisse liefert, ohne Verspätungen oder Kommunikationsfehler. Auf diesem Wege lägen Untersuchungsergebnisse schneller vor und die Initialtherapie könnte schneller beginnen. $\mathrm{Ob}$ dies die Patientenversorgung nachweislich verbessert müssen weitere Untersuchungen zeigen. 


\section{Literaturverzeichnis}

Adams K, Shah PL, Edmonds L, Lim E (2009): Test performance of endobronchial ultrasound and transbronchial needle aspiration biopsy for mediastinal staging in patients with lung cancer: systematic review and meta-analysis. Thorax $\underline{64}$, 757-762

Akopyan G, Bonavida B (2006): Understanding tobacco smoke carcinogen NNK and lung tumorigenesis. Int J Oncol 29, 745-752

Albain KS, Crowley JJ, LeBlanc M, Livingston RB (1990): Determinants of improved outcome in small-cell lung cancer: an analysis of the 2,580-patient Southwest Oncology Group data base. J Clin Oncol $\underline{8}, 1563-1574$

Albain KS, Swann RS, Rusch VW, Turrisi, Andrew T 3rd, Shepherd FA, Smith C, Chen Y, Livingston RB, Feins RH, Gandara DR (2009): Radiotherapy plus chemotherapy with or without surgical resection for stage III non-small-cell lung cancer: a phase III randomised controlled trial. Lancet (London, England) 374, 379-386

Altman DG, Bland JM (1994): Diagnostic tests. 1: Sensitivity and specificity. BMJ $\underline{308}$, 1552

Alvarado-Luna G, Morales-Espinosa D (2016): Treatment for small cell lung cancer, where are we now?-a review. Translational lung cancer research $\underline{5}, 26-38$

Andrews DW, Scott CB, Sperduto PW, Flanders AE, Gaspar LE, Schell MC, WernerWasik M, Demas W, Ryu J, Bahary J (2004): Whole brain radiation therapy with or without stereotactic radiosurgery boost for patients with one to three brain metastases: phase III results of the RTOG 9508 randomised trial. Lancet (London, England) $\underline{363}$, $1665-1672$

Arastéh K, Baenkler H: Innere Medizin: 643 Tabellen (Thieme Electronic Book Library), 2., vollst. überarb. und erw. Aufl. Thieme, Stuttgart 2009

Arriagada R, Bergman B, Dunant A, Le Chevalier T, Pignon J, Vansteenkiste J (2004): Cisplatin-based adjuvant chemotherapy in patients with completely resected non-small-cell lung cancer. New Engl J Med 350, 351-360

Arriagada R, Le Chevalier T, Riviere A, Chomy P, Monnet I, Bardet E, Santos-Miranda JA, Le Pehoux C, Tarayre M, Benhamou S (2002): Patterns of failure after prophylactic cranial irradiation in small-cell lung cancer: analysis of 505 randomized patients. Ann Oncol $\underline{13}, 748-754$

Barlesi F, Scherpereel A, Rittmeyer A, Pazzola A, Ferrer Tur N, Kim J, Ahn M, Aerts, Joachim G J V, Gorbunova V, Vikstrom A (2013): Randomized phase III trial of maintenance bevacizumab with or without pemetrexed after first-line induction with bevacizumab, cisplatin, and pemetrexed in advanced nonsquamous non-small-cell lung cancer: AVAPERL (MO22089). J Clin Oncol 31, 3004-3011

Barlési F, Doddoli C, Greillier L, Dutau H, Astoul P (2006): Bronchoscopy in the diagnosis of lung cancer: an evaluation of current practice. Rev Mal Respir 23, 4S17-4S26

Becker HD, Shirakawa T, Tanaka F, Müller KM, Herth F (1998): Transbronchial lung biopsy in the immunocompromised patient. Eur Respir Mon 9, 193-208

Belinsky SA, Devereux TR, Maronpot RR, Stoner GD, Anderson MW (1989):

Relationship between the formation of promutagenic adducts and the activation of the K- 
ras protooncogene in lung tumors from A/J mice treated with nitrosamines. Cancer Res $\underline{49}$, $5305-5311$

Bender R (2001): Interpretation von Effizienzmaßen der Vierfeldertafel für Diagnostik und Behandlung. Medizinische Klinik 96, 116-121

Birim O, Maat, A P W M, Kappetein AP, van Meerbeeck, J P, Damhuis, R A M, Bogers, A J J C (2003): Validation of the Charlson comorbidity index in patients with operated primary non-small cell lung cancer. Eur J Cardiothorac Surg 23, 30-34

Boffetta P, Agudo A, Ahrens W, Benhamou E, Benhamou S, Darby SC, Ferro G, Fortes C, Gonzalez CA, Jockel KH (1998): Multicenter case-control study of exposure to environmental tobacco smoke and lung cancer in Europe. J Natl Cancer Inst 90, 14401450

Bolliger CT, Mathur PN: Interventional Bronchoscopy. Karger, Basel 2000

Bonifazi M, Sediari M, Ferretti M, Poidomani G, Tramacere I, Mei F, Zuccatosta L, Gasparini S (2014): The Role of the Pulmonologist in Rapid On-site Cytologic Evaluation of Transbronchial Needle Aspiration. Chest 145, 60

Chan BA, Coward, Jermaine I G (2013): Chemotherapy advances in small-cell lung cancer. J Thorac Dis $\underline{5}$, S565-78

Chen Y, Wang L, Wang S, Wu B, Wang Z, Chen F, Xiong B (2015): Meta-analysis of postoperative adjuvant chemotherapy without radiotherapy in early stage non-small cell lung cancer. Onco Targets Ther $\underline{8}, 2033-2043$

Cohen J (1960): A Coefficient of Agreement for Nominal Scales. Educational and Psychological Measurement 20, 37-46

Colice GL, Rubins J, Unger M (2003): Follow-up and surveillance of the lung cancer patient following curative-intent therapy. Chest $\underline{123}, 272 \mathrm{~S}-283 \mathrm{~S}$

Colinet B, Jacot W, Bertrand D, Lacombe S, Bozonnat M, Daures J, Pujol J (2005): A new simplified comorbidity score as a prognostic factor in non-small-cell lung cancer patients: description and comparison with the Charlson's index. Br J Cancer 93, 1098-1105

Cortese DA, McDougall JC (1979): Biopsy and brushing of peripheral lung cancer with fluoroscopic guidance. Chest $\underline{75,141-5}$

Darling GE, Maziak DE, Inculet RI, Gulenchyn KY, Driedger AA, Ung YC, Gu C, Kuruvilla MS, Cline KJ, Julian JA (2011): Positron emission tomography-computed tomography compared with invasive mediastinal staging in non-small cell lung cancer: results of mediastinal staging in the early lung positron emission tomography trial. J Thorac Oncol $\underline{6}, 1367-1372$

Denissenko MF, Pao A, Tang M, Pfeifer GP (1996): Preferential formation of benzoapyrene adducts at lung cancer mutational hotspots in P53. Science 274, 430-432

Detterbeck FC: Diagnosis and treatment of lung cancer: An evidence-based guide for the practicing clinician. W.B. Saunders Co., Philadelphia 2001

Detterbeck FC, Lewis SZ, Diekemper R, Addrizzo-Harris D, Alberts, W. Michael (2013): Executive summary: Diagnosis and management of lung cancer, 3rd ed: american college of chest physicians evidence-based clinical practice guidelines. Chest $\underline{143}, 7 \mathrm{~S}$ 
Dominicis F de, Fourdrain A, Iquille J, Toublanc B, Francois G, Basille D, Monconduit J, Merlusca G, Jounieaux V, Andrejak C (2015): Results of endobronchial ultrasound-guided transbronchial needle aspiration in lung cancer: Importance of the lymph node involvement prevalence. Rev Pneumol Clin $\underline{71}$, 217-225

Douillard J, Rosell R, Lena M de, Carpagnano F, Ramlau R, Gonzales-Larriba JL, Grodzki T, Pereira JR, Le Groumellec A, Lorusso V (2006): Adjuvant vinorelbine plus cisplatin versus observation in patients with completely resected stage IB-IIIA non-small-cell lung cancer (Adjuvant Navelbine International Trialist Association ANITA): a randomised controlled trial. Lancet Oncol $\underline{7}, 719-727$

Downey RJ, Martini N, Rusch VW, Bains MS, Korst RJ, Ginsberg RJ (1999): Extent of chest wall invasion and survival in patients with lung cancer. Ann Thorac Surg $\underline{68}, 188$ 193

Earl HM, Rudd RM, Spiro SG, Ash CM, James LE, Law CS, Tobias JS, Harper PG, Geddes DM, Eraut D (1991): A randomised trial of planned versus as required chemotherapy in small cell lung cancer: a Cancer Research Campaign trial. Br J Cancer $\underline{64}$, $566-572$

El-Bayoumi E, Silvestri GA (2008): Bronchoscopy for the diagnosis and staging of lung cancer. Semin Respir Crit Care Med 29, 261-270

Ellis JH (1975): Transbronchial lung biopsy via the fiberoptic bronchoscope. Experience with 107 consecutive cases and comparison with bronchial brushing. Chest $\underline{68}, 524$

Ernst A, Anantham D, Eberhardt R, Krasnik M, Herth, Felix J F (2008): Diagnosis of mediastinal adenopathy-real-time endobronchial ultrasound guided needle aspiration versus mediastinoscopy. J Thorac Oncol $\underline{3}, 577-582$

Evison M, Crosbie, Philip A J, Morris J, Martin J, Barber PV, Booton R (2014): A study of patients with isolated mediastinal and hilar lymphadenopathy undergoing EBUS-TBNA. BMJ Open Respir Res 1 , e000040

Ferguson MK, Lehman AG (2003): Sleeve lobectomy or pneumonectomy: optimal management strategy using decision analysis techniques. Ann Thorac Surg 76, 1782-1788

Fergusson RJ, Thomson CS, Brewster DH, Brown PH, Milroy R (2003): Lung cancer: the importance of seeing a respiratory physician. Eur. Respir. J. 21, 606-610

Folch E, Mehta AC (2008): Airway Interventions in the Tracheobronchial Tree. Semin Respir Crit Care Med 29, 441-452

Fox W, Scadding JG (1973): Medical Research Council comparative trial of surgery and radiotherapy for primary treatment of small-celled or oat-celled carcinoma of bronchus. Ten-year follow-up. Lancet (London, England) 2, 63-65

Gaga M, Powell CA, Schraufnagel DE, Schonfeld N, Rabe K, Hill NS, Sculier J (2013): An official American Thoracic Society/European Respiratory Society statement: the role of the pulmonologist in the diagnosis and management of lung cancer. Am J Respir Crit Care Med 188, 503-507

Gasparini S, Ferretti M, Secchi EB, Baldelli S, Zuccatosta L, Gusella P (1995): Integration of transbronchial and percutaneous approach in the diagnosis of peripheral pulmonary nodules or masses. Experience with 1,027 consecutive cases. Chest 108, 131-137 
Gatzemeier U, Pawel JV, Laumen R, Hossfeld DK, Neuhauss R (1994):

Etoposide/vincristine-based chemotherapy with or without carboplatin in extensive-stage small cell lung cancer: a prospective randomized phase III trial. Semin Oncol 21, 31-35

Ginsberg RJ, Rubinstein LV (1995): Randomized trial of lobectomy versus limited resection for T1 N0 non-small cell lung cancer. Lung Cancer Study Group. Ann Thorac Surg $\underline{60}$, 615-22; discussion 622-3

Goeckenjan G, Sitter H, Thomas M, Branscheid D, Flentje M, Griesinger F, Niederle N, Stuschke M, Blum T, Deppermann K (2010): Prävention, Diagnostik, Therapie und Nachsorge des Lungenkarzinoms. Pneumologie $\underline{64}$, e1-e164

Gore EM, Bae K, Wong SJ, Sun A, Bonner JA, Schild SE, Gaspar LE, Bogart JA, WernerWasik M, Choy H (2011): Phase III comparison of prophylactic cranial irradiation versus observation in patients with locally advanced non-small-cell lung cancer: primary analysis of radiation therapy oncology group study RTOG 0214. J Clin Oncol 29, 272-278

Govert JA, Dodd LG, Kussin PS, Samuelson WM (1999): A prospective comparison of fiberoptic transbronchial needle aspiration and bronchial biopsy for bronchoscopically visible lung carcinoma. Cancer $\underline{87}, 129-134$

Gregor A, Drings P, Burghouts J, Postmus PE, Morgan D, Sahmoud T, Kirkpatrick A, Dalesio O, Giaccone G (1997): Randomized trial of alternating versus sequential radiotherapy/chemotherapy in limited-disease patients with small-cell lung cancer: a European Organization for Research and Treatment of Cancer Lung Cancer Cooperative Group Study. J Clin Oncol 15, 2840-2849

Harrow EM, Abi-Saleh W, Blum J, Harkin T, Gasparini S, Addrizzo-Harris DJ, Arroliga AC, Wight G (2000): The Utility of Transbronchial Needle Aspiration in the Staging of Bronchogenic Carcinoma. Am J Respir Crit Care Med 161, 601-607

Herth FJ (2011): Bronchoscopic techniques in diagnosis and staging of lung cancer. Breathe $\underline{7}, 324-337$

Herth FJ, Eberhardt R (2004): Interventional bronchoscopy. Minvera Pneumol 43, 189201

Herth, Felix J. F, Ernst A (2005): Innovative bronchoscopic diagnostic techniques: endobronchial ultrasound and electromagnetic navigation. Curr Opin Pulm Med $\underline{11}$ Hetzel J, Eberhardt R, Herth, F J F, Petermann C, Reichle G, Freitag L, Dobbertin I, Franke KJ, Stanzel F, Beyer T (2012): Cryobiopsy increases the diagnostic yield of endobronchial biopsy: a multicentre trial. Eur. Respir. J. 39, 685-690

Hetzel J, Hetzel M, Hasel C, Moeller P, Babiak A (2008): Old meets modern: the use of traditional cryoprobes in the age of molecular biology. Respiration $\underline{76}$, 193-197

Hoffman PC, Mauer AM, Vokes EE (2000): Lung cancer. Lancet (London, England) 355, $479-485$

Hoffmann D, Djordjevic MV, Rivenson A, Zang E, Desai D, Amin S (1993): A study of tobacco carcinogenesis. LI. Relative potencies of tobacco-specific N-nitrosamines as inducers of lung tumours in A/J mice. Cancer Lett $\underline{71}, 25-30$ 
Jackson Ch.: The Life of Chevalier Jackson: An Autobiography. Macmillan, New Yorck 1938

Jackson, D V Jr, Zekan PJ, Caldwell RD, Slatkoff ML, Harding RW, Case LD, Hopkins JO, Muss HB, Richards F2, White DR (1984): VP-16-213 in combination chemotherapy with chest irradiation for small-cell lung cancer: a randomized trial of the Piedmont Oncology Association. J Clin Oncol 2, 1343-1351

Jett JR, Everson L, Therneau TM, Krook JE, Dalton RJ, Marschke, R F Jr, Veeder MH, Brunk SF, Mailliard JA, Twito DI (1990): Treatment of limited-stage small-cell lung cancer with cyclophosphamide, doxorubicin, and vincristine with or without etoposide: a randomized trial of the North Central Cancer Treatment Group. J Clin Oncol $\underline{8}$, 33-38

Karim SM, Zekri J (2012): Chemotherapy for small cell lung cancer: a comprehensive review. Oncology reviews $\underline{6}$, e4

Killian G (1898): Ueber directe bronchoscopie. MMW 27, 844-847

Landis JR, Koch GG (1977): The measurement of observer agreement for categorical data. Biometrics $\underline{33}, 159-174$

Lassen U, Osterlind K, Hansen M, Dombernowsky P, Bergman B, Hansen HH (1995): Long-term survival in small-cell lung cancer: posttreatment characteristics in patients surviving 5 to $18+$ years--an analysis of 1,714 consecutive patients. J Clin Oncol $\underline{13}$, 12151220

Lebeau B, Urban T, Brechot JM, Paillotin D, Vincent J, Leclerc P, Meekel P, L'Her P, Lebas FX, Chastang C (1999): A randomized clinical trial comparing concurrent and alternating thoracic irradiation for patients with limited small cell lung carcinoma. "Petites Cellules" Group. Cancer 흐, 1480-1487

Liam CK, Pang YK, Poosparajah S (2007): Diagnostic yield of flexible bronchoscopic procedures in lung cancer patients according to tumour location. Singapore Med J $\underline{48}, 625$ 631

Lowenbraun S, Bartolucci A, Smalley RV, Lynn M, Krauss S, Durant JR (1979): The superiority of combination chemotherapy over single agent chemotherapy in small cell lung carcinoma. Cancer $\underline{44}$, 406-413

Ludbrook, Joanna J S, Truong PT, MacNeil MV, Lesperance M, Webber A, Joe H, Martins H, Lim J (2003): Do age and comorbidity impact treatment allocation and outcomes in limited stage small-cell lung cancer? a community-based population analysis. Int J Radiat Oncol Biol Phys 포, 1321-1330

Magdeleinat P, Alifano M, Benbrahem C, Spaggiari L, Porrello C, Puyo P, Levasseur P, Regnard JF (2001): Surgical treatment of lung cancer invading the chest wall: results and prognostic factors. Ann Thorac Surg 71, 1094-1099

Malvezzi M, Bertuccio P, Rosso T, Rota M, Levi F, La Vecchia C, Negri E (2015):

European cancer mortality predictions for the year 2015: does lung cancer have the highest death rate in EU women? Ann Oncol 26, 779-786

Mascaux C, Paesmans M, Berghmans T, Branle F, Lafitte JJ, Lemaitre F, Meert AP, Vermylen P, Sculier JP (2000): A systematic review of the role of etoposide and cisplatin 
in the chemotherapy of small cell lung cancer with methodology assessment and metaanalysis. Lung cancer (Amsterdam, Netherlands) $\underline{30}$, 23-36

Mazzone P, Jain P, Arroliga AC, Matthay RA (2002): Bronchoscopy and needle biopsy techniques for diagnosis and staging of lung cancer. Clin Chest Med 23, 137-158

McCaughan BC, Martini N, Bains MS, McCormack PM (1985): Chest wall invasion in carcinoma of the lung. Therapeutic and prognostic implications. J Thorac Cardiovasc Surg $\underline{89}, 836-841$

McCracken JD, Janaki LM, Crowley JJ, Taylor SA, Giri PG, Weiss GB, Gordon W, JR, Baker LH, Mansouri A, Kuebler JP (1990): Concurrent chemotherapy/radiotherapy for limited small-cell lung carcinoma: a Southwest Oncology Group Study. J Clin Oncol $\underline{8}$, 892-898

Meert AP, Paesmans M, Berghmans T, Martin B, Mascaux C, Vallot F, Verdebout JM, Lafitte JJ, Sculier JP (2001): Prophylactic cranial irradiation in small cell lung cancer: a systematic review of the literature with meta-analysis. BMC cancer $\underline{1}, 5$

Mehta MP, Rodrigus P, Terhaard, C H J, Rao A, Suh J, Roa W, Souhami L, Bezjak A, Leibenhaut M, Komaki R (2003): Survival and neurologic outcomes in a randomized trial of motexafin gadolinium and whole-brain radiation therapy in brain metastases. J Clin Oncol 21, 2529-2536

Mok TS, Wu Y, Thongprasert S, Yang C, Chu D, Saijo N, Sunpaweravong P, Han B, Margono B, Ichinose Y (2009): Gefitinib or carboplatin-paclitaxel in pulmonary adenocarcinoma. New Engl J Med 361, 947-957

Moreira AL, Eng J (2014): Personalized therapy for lung cancer. Chest 146, 1649-1657

Mountain CF (1997): Revisions in the International System for Staging Lung Cancer. Chest $\underline{111}, 1710-1717$

Navani N, Lawrence DR, Kolvekar S, Hayward M, McAsey D, Kocjan G, Falzon M, Capitanio A, Shaw P, Morris S (2012): Endobronchial ultrasound-guided transbronchial needle aspiration prevents mediastinoscopies in the diagnosis of isolated mediastinal lymphadenopathy: a prospective trial. Am J Respir Crit Care Med 186, 255-260

Nizzoli R, Tiseo M, Gelsomino F, Bartolotti M, Majori M, Ferrari L, Filippo M de, Rindi G, Silini EM, Guazzi A (2011): Accuracy of fine needle aspiration cytology in the pathological typing of non-small cell lung cancer. J Thorac Oncol $\underline{6}$, 489-493

Ohata M (1998): History and progress of bronchology in Japan. 気管支学: 日本気管支研 究会雑誌 20, 539-546

Okada M, Nishio W, Sakamoto T, Uchino K, Yuki T, Nakagawa A, Tsubota N (2004): Evolution of surgical outcomes for nonsmall cell lung cancer: time trends in 1465 consecutive patients undergoing complete resection. Ann Thorac Surg 77, 1926-30; discussion 1931

Okada M, Yoshikawa K, Hatta T, Tsubota N (2001): Is segmentectomy with lymph node assessment an alternative to lobectomy for non-small cell lung cancer of $2 \mathrm{~cm}$ or smaller? Ann Thorac Surg 71, 956-60; discussion 961 
Osterlind K, Hansen M, Hansen HH, Dombernowsky P, Rorth M (1985): Treatment policy of surgery in small cell carcinoma of the lung: retrospective analysis of a series of 874 consecutive patients. Thorax $\underline{40}, 272-277$

Paech DC, Weston AR, Pavlakis N, Gill A, Rajan N, Barraclough H, Fitzgerald B, van Kooten M (2011): A Systematic Review of the Interobserver Variability for Histology in the Differentiation between Squamous and Nonsquamous Non-small Cell Lung Cancer. Journal of Thoracic Oncology $\underline{6}, 55-63$

Perry MC, Eaton WL, Propert KJ, Ware JH, Zimmer B, Chahinian AP, Skarin A, Carey RW, Kreisman H, Faulkner C (1987): Chemotherapy with or without radiation therapy in limited small-cell carcinoma of the lung. New Engl J Med 316, 912-918

Perry MC, Herndon, J E 3rd, Eaton WL, Green MR (1998): Thoracic radiation therapy added to chemotherapy for small-cell lung cancer: an update of Cancer and Leukemia Group B Study 8083. J Clin Oncol 16, 2466-2467

Pignon J, Tribodet H, Scagliotti GV, Douillard J, Shepherd FA, Stephens RJ, Dunant A, Torri V, Rosell R, Seymour L (2008): Lung adjuvant cisplatin evaluation: a pooled analysis by the LACE Collaborative Group. J Clin Oncol 26, 3552-3559

Pignon JP, Arriagada R, Ihde DC, Johnson DH, Perry MC, Souhami RL, Brodin O, Joss RA, Kies MS, Lebeau B (1992): A meta-analysis of thoracic radiotherapy for small-cell lung cancer. New Engl J Med 327, 1618-1624

Pijls-Johannesma, M C G, Ruysscher D de, Lambin P, Rutten I, Vansteenkiste JF (2005): Early versus late chest radiotherapy for limited stage small cell lung cancer. Cochrane Database Syst Rev, CD004700

Pilkington G, Boland A, Brown T, Oyee J, Bagust A, Dickson R (2015): A systematic review of the clinical effectiveness of first-line chemotherapy for adult patients with locally advanced or metastatic non-small cell lung cancer. Thorax $\underline{70}$, 359-367

Pirker R, Pereira JR, Pawel J von, Krzakowski M, Ramlau R, Park K, Marinis F de, Eberhardt, Wilfried E E, Paz-Ares L, Storkel S (2012): EGFR expression as a predictor of survival for first-line chemotherapy plus cetuximab in patients with advanced non-smallcell lung cancer: analysis of data from the phase 3 FLEX study. Lancet Oncol 13, 33-42

Pirker R, Pereira JR, Szczesna A, Pawel J von, Krzakowski M, Ramlau R, Vynnychenko I, Park K, Yu C, Ganul V (2009): Cetuximab plus chemotherapy in patients with advanced non-small-cell lung cancer (FLEX): an open-label randomised phase III trial. Lancet (London, England) $\underline{373}$, 1525-1531

Postmus PE, Haaxma-Reiche H, Smit EF, Groen HJ, Karnicka H, Lewinski T, van Meerbeeck J, Clerico M, Gregor A, Curran D (2000): Treatment of brain metastases of small-cell lung cancer: comparing teniposide and teniposide with whole-brain radiotherapy--a phase III study of the European Organization for the Research and Treatment of Cancer Lung Cancer Cooperative Group. J Clin Oncol 18, 3400-3408

Postmus PE, Scagliotti G, Groen HJ, Gozzelino F, Burghouts JT, Curran D, Sahmoud T, Kirkpatrick A, Giaccone G, Splinter TA (1996): Standard versus alternating non-crossresistant chemotherapy in extensive small cell lung cancer: an EORTC Phase III trial. Eur J Cancer (Oxford, England 1990) 32A, 1498-1503 
Pottgen C, Eberhardt W, Grannass A, Korfee S, Stuben G, Teschler H, Stamatis G, Wagner H, Passlick B, Petersen V (2007): Prophylactic cranial irradiation in operable stage IIIA non small-cell lung cancer treated with neoadjuvant chemoradiotherapy: results from a German multicenter randomized trial. J Clin Oncol 25, 4987-4992

Pujol JL, Carestia L, Daures JP (2000): Is there a case for cisplatin in the treatment of small-cell lung cancer? A meta-analysis of randomized trials of a cisplatin-containing regimen versus a regimen without this alkylating agent. Br J Cancer $\underline{83}, 8-15$

Ranson M, Davidson N, Nicolson M, Falk S, Carmichael J, Lopez P, Anderson H, Gustafson N, Jeynes A, Gallant G (2000): Randomized trial of paclitaxel plus supportive care versus supportive care for patients with advanced non-small-cell lung cancer. J Natl Cancer Inst 92, 1074-1080

Reck M, Pawel J von, Zatloukal P, Ramlau R, Gorbounova V, Hirsh V, Leighl N, Mezger J, Archer V, Moore N (2010): Overall survival with cisplatin-gemcitabine and bevacizumab or placebo as first-line therapy for nonsquamous non-small-cell lung cancer: results from a randomised phase III trial (AVAiL). Ann Oncol 21, 1804-1809

Robert-Koch-Institut (2013): Krebs in Deutschland 2009/2010

Robinson LA, Ruckdeschel JC, Wagner H, JR, Stevens CW (2007): Treatment of nonsmall cell lung cancer-stage IIIA: ACCP evidence-based clinical practice guidelines (2nd edition). Chest $\underline{132}, 243 \mathrm{~S}-265 \mathrm{~S}$

Rowell NP, Williams CJ (2001): Radical radiotherapy for stage I/II non-small cell lung cancer in patients not sufficiently fit for or declining surgery (medically inoperable).

Cochrane Database Syst Rev, CD002935

Rusch VW, Asamura H, Watanabe H, Giroux DJ, Rami-Porta R, Goldstraw P (2009): The IASLC lung cancer staging project: a proposal for a new international lymph node map in the forthcoming seventh edition of the TNM classification for lung cancer. $J$ Thorac Oncol $\underline{4}, 568-577$

Ruysscher D de, Pijls-Johannesma M, Bentzen SM, Minken A, Wanders R, Lutgens L, Hochstenbag M, Boersma L, Wouters B, Lammering G (2006): Time between the first day of chemotherapy and the last day of chest radiation is the most important predictor of survival in limited-disease small-cell lung cancer. J Clin Oncol 24, 1057-1063

Sandler A, Gray R, Perry MC, Brahmer J, Schiller JH, Dowlati A, Lilenbaum R, Johnson DH (2006): Paclitaxel-carboplatin alone or with bevacizumab for non-small-cell lung cancer. New Engl J Med 355, 2542-2550

Sawada S, Komori E, Nogami N, Bessho A, Segawa Y, Shinkai T, Nakata M, Yamashita M (2005): Advanced age is not correlated with either short-term or long-term postoperative results in lung cancer patients in good clinical condition. Chest $\underline{128}, 1557-1563$

Schreiber G, McCrory DC (2003): Performance characteristics of different modalities for diagnosis of suspected lung cancer: summary of published evidence. Chest $\underline{123}, 115 \mathrm{~S}-$ $128 \mathrm{~S}$

Sculier JP, Berghmans T, Castaigne C, Luce S, Sotiriou C, Vermylen P, Paesmans M (1998): Maintenance chemotherapy for small cell lung cancer: a critical review of the literature. Lung cancer (Amsterdam, Netherlands) $\underline{19}, 141-151$ 
Sedrakyan A, Van Der Meulen, Jan, O'Byrne K, Prendiville J, Hill J, Treasure T (2004): Postoperative chemotherapy for non-small cell lung cancer: A systematic review and metaanalysis. J Thorac Cardiovasc Surg $\underline{128}$, 414-419

Seute T, Leffers P, Wilmink JT, ten Velde, Guul P M, Twijnstra A (2006): Response of asymptomatic brain metastases from small-cell lung cancer to systemic first-line chemotherapy. J Clin Oncol 24, 2079-2083

Shepherd FA, Ginsberg RJ, Feld R, Evans WK, Johansen E (1991): Surgical treatment for limited small-cell lung cancer. The University of Toronto Lung Oncology Group experience. J Thorac Cardiovasc Surg 101, 385-393

Sim J, Wright CC (2005): The kappa statistic in reliability studies: use, interpretation, and sample size requirements. Phys Ther $\underline{85}, 257-268$

Singh S, Parulekar W, Murray N, Feld R, Evans WK, Tu D, Shepherd FA (2005): Influence of sex on toxicity and treatment outcome in small-cell lung cancer. J Clin Oncol $\underline{23}, 850-856$

Skov BG, Baandrup U, Jakobsen GK, Kiss K, Krasnik M, Rossen K, Vilmann P (2007): Cytopathologic diagnoses of fine-needle aspirations from endoscopic ultrasound of the mediastinum. Cancer 111, 234-241

Skov BG, Kiss K, Ramsted J, Linnemann D (2009): A technique to improve diagnostic information from fine-needle aspirations: immunohistochemistry on cytoscrape. Cancer $\underline{117}, 120-127$

Slotman B, Faivre-Finn C, Kramer G, Rankin E, Snee M, Hatton M, Postmus P, Collette L, Musat E, Senan S (2007): Prophylactic cranial irradiation in extensive small-cell lung cancer. New Engl J Med 357, 664-672

Slotman BJ, Mauer ME, Bottomley A, Faivre-Finn C, Kramer, Gijs W P M, Rankin EM, Snee M, Hatton M, Postmus PE, Collette L (2009): Prophylactic cranial irradiation in extensive disease small-cell lung cancer: short-term health-related quality of life and patient reported symptoms: results of an international Phase III randomized controlled trial by the EORTC Radiation Oncology and Lung Cancer Groups. J Clin Oncol 27, 78-84

Smith CJ, Perfetti TA, Mullens MA, Rodgman A, Doolittle DJ (2000a): "IARC group 2B Carcinogens" reported in cigarette mainstream smoke. Food Chem Toxicol $\underline{38}$, 825-848

Smith CJ, Perfetti TA, Rumple MA, Rodgman A, Doolittle DJ (2000b): "IARC group 2A Carcinogens" reported in cigarette mainstream smoke. Food Chem Toxicol 38, 371-383

Souhami RL, Law K (1990): Longevity in small cell lung cancer. A report to the Lung Cancer Subcommittee of the United Kingdom Coordinating Committee for Cancer Research. Br J Cancer 61, 584-589

Souhami RL, Spiro SG, Rudd RM, Ruiz de Elvira, M C, James LE, Gower NH, Lamont A, Harper PG (1997): Five-day oral etoposide treatment for advanced small-cell lung cancer: randomized comparison with intravenous chemotherapy. J Natl Cancer Inst $\underline{89}, 577-580$

Spiro SG, Rudd RM, Souhami RL, Brown J, Fairlamb DJ, Gower NH, Maslove L, Milroy R, Napp V, Parmar, M K B (2004): Chemotherapy versus supportive care in advanced non-small cell lung cancer: improved survival without detriment to quality of life. Thorax $\underline{59}, 828-836$ 
Spiro SG, Souhami RL, Geddes DM, Ash CM, Quinn H, Harper PG, Tobias JS, Partridge M, Eraut D (1989): Duration of chemotherapy in small cell lung cancer: a Cancer Research Campaign trial. Br J Cancer 59, 578-583

Statistisches Bundesamt (Destatis) (2014): Die 10 häufigsten Todesfälle durch Krebserkrankungen.

https://www.destatis.de/DE/ZahlenFakten/GesellschaftStaat/Gesundheit/Todesursachen/Ta bellen/Krebserkrankungen.html; Zugriff am 8.5.15

Steinfort DP, Russell PA, Tsui A, White G, Wright G, Irving LB (2012): Interobserver agreement in determining non-small cell lung cancer subtype in specimens acquired by EBUS-TBNA. Eur Respir J $\underline{40}$, 699-705

Suh JH, Stea B, Nabid A, Kresl JJ, Fortin A, Mercier J, Senzer N, Chang EL, Boyd AP, Cagnoni PJ (2006): Phase III study of efaproxiral as an adjunct to whole-brain radiation therapy for brain metastases. J Clin Oncol 24, 106-114

Sundstrom S, Bremnes RM, Kaasa S, Aasebo U, Hatlevoll R, Dahle R, Boye N, Wang M, Vigander T, Vilsvik J (2002): Cisplatin and etoposide regimen is superior to cyclophosphamide, epirubicin, and vincristine regimen in small-cell lung cancer: results from a randomized phase III trial with 5 years' follow-up. J Clin Oncol $\underline{20}$, 4665-4672

Thomas, C R Jr, Giroux DJ, Janaki LM, Turrisi, A T 3rd, Crowley JJ, Taylor SA, McCracken JD, Shankir Giri, P G, Gordon W, JR, Livingston RB (2001): Ten-year followup of Southwest Oncology Group 8269: a phase II trial of concomitant cisplatin-etoposide and daily thoracic radiotherapy in limited small-cell lung cancer. Lung cancer (Amsterdam, Netherlands) 33, 213-219

Thongprasert S, Sanguanmitra P, Juthapan W, Clinch J (1999): Relationship between quality of life and clinical outcomes in advanced non-small cell lung cancer: best supportive care (BSC) versus BSC plus chemotherapy. Lung cancer (Amsterdam, Netherlands) 24, 17-24

Travis WD (2002): Pathology of lung cancer. Clin Chest Med 23, 65-81, viii

Tsao MN, Lloyd N, Wong R, Chow E, Rakovitch E, Laperriere N (2006): Whole brain radiotherapy for the treatment of multiple brain metastases. Cochrane Database Syst Rev, CD003869

Tsao MN, Lloyd N, Wong, Rebecca K S, Chow E, Rakovitch E, Laperriere N, Xu W, Sahgal A (2012): Whole brain radiotherapy for the treatment of newly diagnosed multiple brain metastases. Cochrane Database Syst Rev, CD003869

Tsuchiya R, Suzuki K, Ichinose Y, Watanabe Y, Yasumitsu T, Ishizuka N, Kato H (2005): Phase II trial of postoperative adjuvant cisplatin and etoposide in patients with completely resected stage I-IIIa small cell lung cancer: the Japan Clinical Oncology Lung Cancer Study Group Trial (JCOG9101). J Thorac Cardiovasc Surg 129, 977-983

Ulsperger E, Karrer K, Denck H (1991): Multimodality treatment for small cell bronchial carcinoma. Preliminary results of a prospective, multicenter trial. The ISC-Lung Cancer Study Group. Eur J Cardiothorac Surg 5, 306-9; discussion 310 
Um S, Kim HK, Jung S, Han J, Lee KJ, Park HY, Choi YS, Shim YM, Ahn M, Park K (2015): Endobronchial ultrasound versus mediastinoscopy for mediastinal nodal staging of non-small-cell lung cancer. J Thorac Oncol 10, 331-337

Ung YC, Maziak DE, Vanderveen JA, Smith CA, Gulenchyn K, Lacchetti C, Evans WK (2007): 18Fluorodeoxyglucose positron emission tomography in the diagnosis and staging of lung cancer: a systematic review. J Natl Cancer Inst 99, 1753-1767

Urban T, Baleyte T, Chastang CL, Jeannin L, Delaval P, Zaegel M, Mornet M, Coetmeur D, Lebeau B (1999): Standard combination versus alternating chemotherapy in small cell lung cancer: a randomised clinical trial including 394 patients. 'Petites Cellules' Group. Lung cancer (Amsterdam, Netherlands) 25, 105-113

van der Heijden, Erik H F M, Casal RF, Trisolini R, Steinfort DP, Hwangbo B, Nakajima T, Guldhammer-Skov B, Rossi G, Ferretti M, Herth, Felix F J (2014): Guideline for the acquisition and preparation of conventional and endobronchial ultrasound-guided transbronchial needle aspiration specimens for the diagnosis and molecular testing of patients with known or suspected lung cancer. Respiration $\underline{88}, 500-517$

Videtic, Gregory M M, Stitt LW, Dar AR, Kocha WI, Tomiak AT, Truong PT, Vincent MD, Yu EW (2003): Continued cigarette smoking by patients receiving concurrent chemoradiotherapy for limited-stage small-cell lung cancer is associated with decreased survival. J Clin Oncol 21, 1544-1549

Villamizar N, Swanson SJ (2014): Lobectomy vs. segmentectomy for NSCLC. Ann Cardiothorac Surg $\underline{3}, 160-166$

Waddell TK, Shepherd FA (2004): Should aggressive surgery ever be part of the management of small cell lung cancer? Thoracic surgery clinics $\underline{14}, 271-281$

Wahi R, McMurtrey MJ, DeCaro LF, Mountain CF, Ali MK, Smith TL, Roth JA (1989): Determinants of perioperative morbidity and mortality after pneumonectomy. Ann Thorac Surg $\underline{48}, 33-37$

Wahidi MM, Herth, Felix J F, Ernst A (2007): State of the art: interventional pulmonology. Chest $\underline{131}, 261-274$

Wang KP (1994): Staging of bronchogenic carcinoma by bronchoscopy. Chest $\underline{106}, 588-$ 593

Wang KP, Terry PB (1983): Transbronchial needle aspiration in the diagnosis and staging of bronchogenic carcinoma. Am Rev Respir Dis 127, 344-347

Warde P, Payne D (1992): Does thoracic irradiation improve survival and local control in limited-stage small-cell carcinoma of the lung? A meta-analysis. J Clin Oncol 10, 890-895

Weinmann M, Jeremic B, Toomes H, Friedel G, Bamberg M (2003): Treatment of lung cancer in the elderly. Part I: non-small cell lung cancer. Lung cancer (Amsterdam, Netherlands) 39, 233-253

White SC, Anderson H, Jayson GC, Ashcroft L, Ranson M, Thatcher N (2000):

Randomised phase II study of cisplatin-etoposide versus infusional carboplatin in advanced non-small-cell lung cancer and mesothelioma. Ann Oncol 11, 201-206 
Winton T, Livingston R, Johnson D, Rigas J, Johnston M, Butts C, Cormier Y, Goss G, Inculet R, Vallieres E (2005): Vinorelbine plus cisplatin vs. observation in resected nonsmall-cell lung cancer. New Engl JMed 352, 2589-2597

Wolf M, Havemann K, Holle R, Harms V, Drings P, Hans K, Dombrowski H, Victor N (1987): The prognostic value of response to the first cycle of chemotherapy in small cell lung cancer. Results of a multicenter German trial. Eur J Cancer 23, 1197-1205

Wolf M, Holle R, Hans K, Drings P, Havemann K (1991): Analysis of prognostic factors in 766 patients with small cell lung cancer (SCLC): the role of sex as a predictor for survival. Br J Cancer 63, 986-992

Wright G, Manser RL, Byrnes G, Hart D, Campbell DA (2006): Surgery for non-small cell lung cancer: systematic review and meta-analysis of randomised controlled trials. Thorax $\underline{61}, 597-603$

Yasufuku K, Nakajima T, Motoori K, Sekine Y, Shibuya K, Hiroshima K, Fujisawa T (2006): Comparison of endobronchial ultrasound, positron emission tomography, and CT for lymph node staging of lung cancer. Chest 130, 710-718

Yung, Rex C W (2003): Tissue diagnosis of suspected lung cancer: selecting between bronchoscopy, transthoracic needle aspiration, and resectional biopsy. Respir Care Clin $\mathrm{N}$ Am $\underline{9}, 51-76$

Zaric B, Stojsic V, Sarcev T, Stojanovic G, Carapic V, Perin B, Zarogoulidis P, Darwiche K, Tsakiridis K, Karapantzos I (2013): Advanced bronchoscopic techniques in diagnosis and staging of lung cancer. J Thorac Dis 5 Suppl 4, S359-70 


\section{Danksagung}

Ich danke Prof. Dr. med. Andreas für die Bereitstellung des Themas sowie der außergewöhnlich guten und zeitnahen Korrekturen der Arbeit. Weiter bin ich Dr. med. Rittmeyer und Dr. med. Zwerger zu Dank verpflichtet, da sie mit der Auswertung der TBNA-Ausstriche in ihrer Freizeit den Grundstein für diese vergleichende Arbeit gelegt haben. Dr. Rittmeyer war mir in fachlichen Fragen ein verlässlicher und ausdauernder, wie auch angenehmer Kollege. Herrn Dr. med. Welker sei für seinen scharfen Verstand bei der Wahl der Ein- und Ausschlusskriterien gedankt, wie auch für die Bereitstellung der Referenzzytologie. 